$$
\text { كلية التجارة بورسعيد }
$$

قسم العلوم السياسية والإدارة العامة

$$
\text { ورقة بحثية }
$$

تطور مفهوم خدمات المواطنين وعلاقته بنظم المعلومات والإتصالات

$$
\text { إعداد }
$$

الباحث / شريف صالح محمد

$$
\text { إثراف }
$$
أ. د / محمد أحمد عبد النعيم
أ.م.د/ شريفة فاضل محمد
أستاذ القانون العام
الأستاذ المساعد - قسم العلوم السياسية
كلية الحقوق
كلية التجارة
جامعة بورسعيد 


\section{تطور مفهوم خدمات المواطنين وعلاقته بنظم المعلومات والإتصالات}

\section{ملخص البحث}

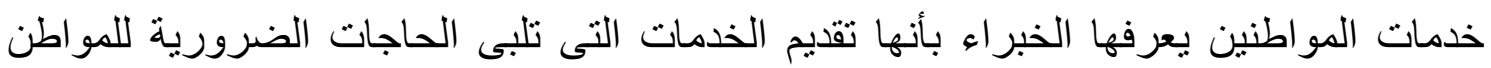

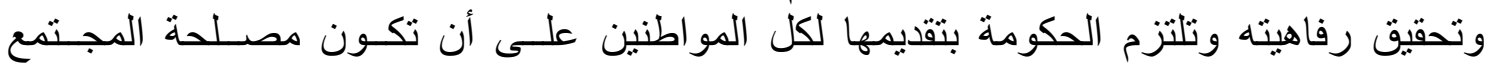

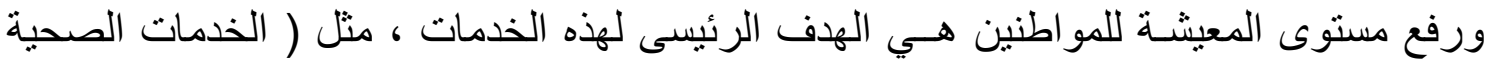

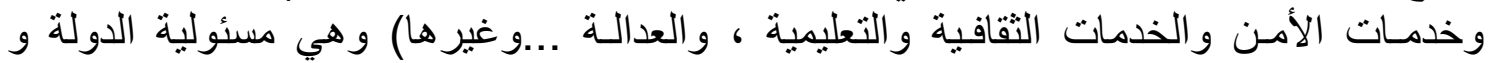

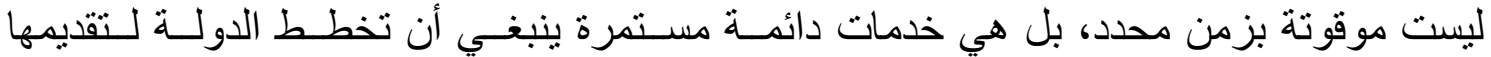
وتطويـر ها ليحصل عليها المواطن فى بسهولة وئلة ويسر.

و التقدم الكبير فى تكنولوجيا المعلومات والإتصالات فرض على على الحكومات والثعوب إستخدام

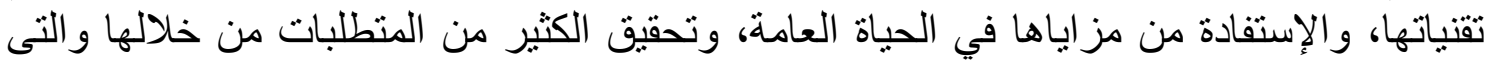

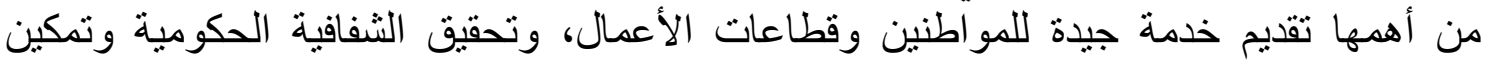

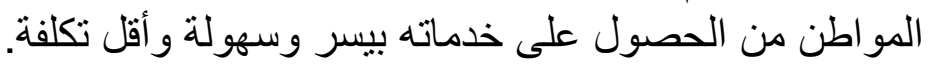

أولاً - مشكلة الدراسة :

تكمن مشكلة هذه الدراسة فى الفجوة بين الدفاهيم التقليدية لتقديم الخدمات العامة والتطورات

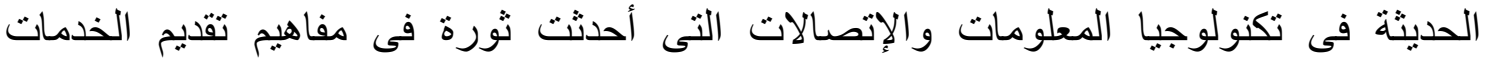

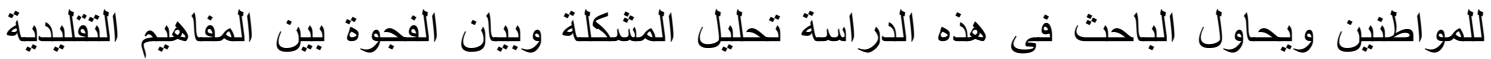

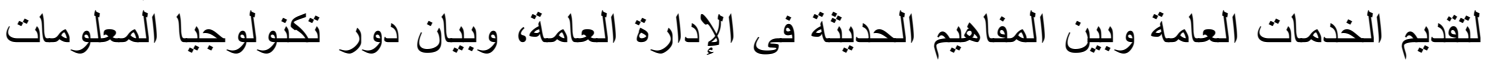
و الإتصالات فى تطوير الخدمات المقدمة للمو اطنين . الإدارة

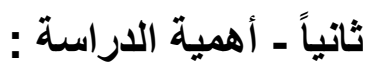

ترجع أهمية تللك الدراسة إلى أنها تحاول بيان الدور الجوهرى الذى تلعبه تكنولوجيا المعلومات

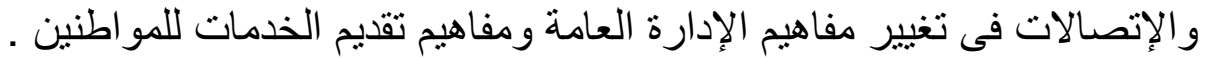
ثالثاً ـ. أهداف الدراسة : الإسي الهاف العام لهذه الدراسة هو التعرف على علاقة تكنولوجيا المعلومات والإتصالات بتغير مفهوم الإدارة العامة وتقديم الخدمات للمو اطنين، ويتفرع منه الأهداف الأتية : 1- تحليل وبيان مفهوم الخدمات العامة .

2- بيان أهمية الخدمات العامة وبيان الوظائف الرئيسية للإدارة العامة. 3- بيان ملامح النموذج التقليدى للإدارة العامة ودو افع التغيير ثم بيان مفهوم ونثأة الإدارة العامة 
4- بيان أثر تكنولوجيا المعلومات فى تطوير مفهوم الخدمات العامة . رابعأ - تساؤلات الدراسة :

تنطلق هذه الدراسة من مقوله رئيسية مؤدا ها أن تكنولوجيا المعلومات والإتصالات أحدثت ثورة

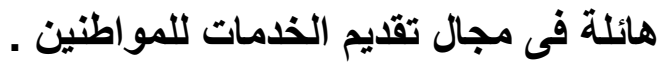

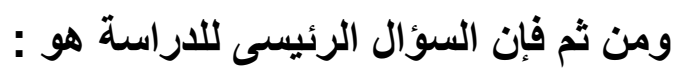
ماهو أثر تكنولوجيا المعلومات فى تطويرمفهوم تقديم الخدمات للمواطنين ؟ ويتفر ع من السؤال الرئيسى للار اسة عدة أسئلة هى : ما هو مفهوم الخدمات العامة ؟

مالمقصود بالإدارة العامة وماهى ملامح الإدارة العامة التقليدية ؟ ماهى دو افع التغيير للإنتقال لمفهوم الإدارة العامة الحديثة ؟ ماهو دور تكنولوحيا المعلومات والإتصالات فى إحداث هذا التغير ؟

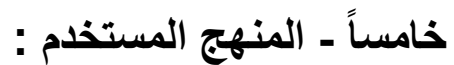
المنهج يعتبر بمثابة العمود الفقرى فى الدراسة وهو البرنامج الذى يحدد السبيل للوصول إلى الحقائق

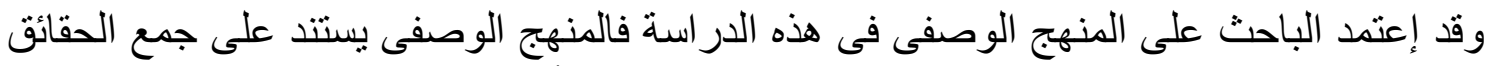

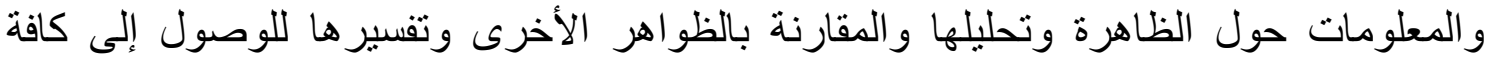

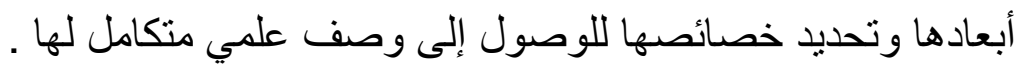




\section{مقدمة}

لقد أدت الثورة المعلوماتية إلى رغبة الحكومات والثعوب في الاستفادة من تقنياتها،

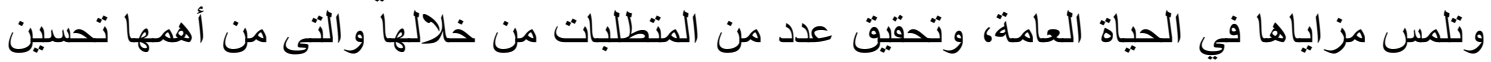

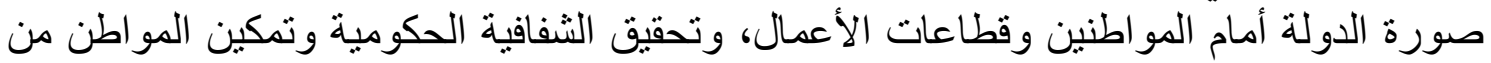

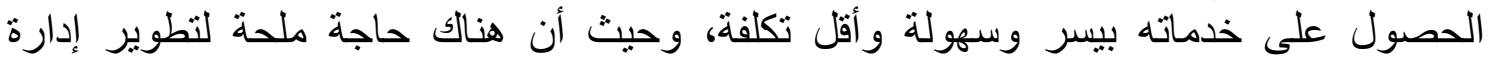

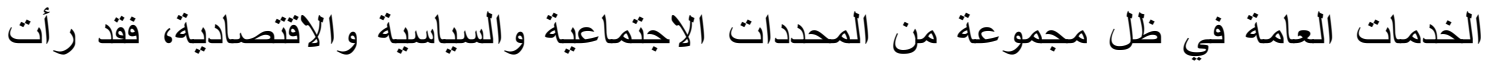

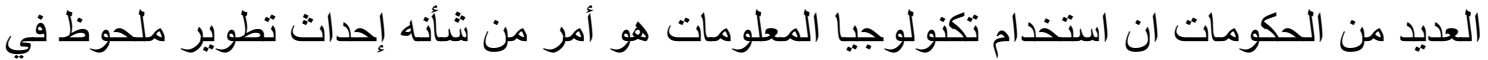

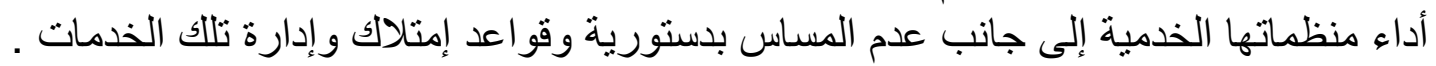

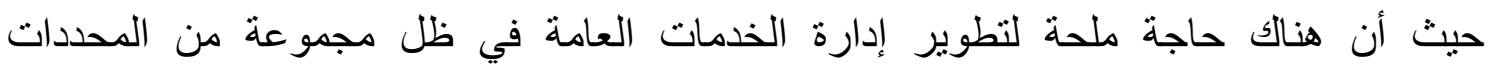

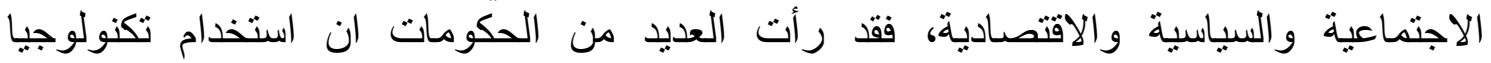

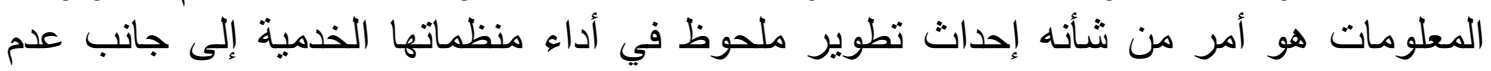
المساس بدنتورية وقو اعد إمتلاك و إدارة تلك الخدات الخدمات.

أولاً : مفهوم الخدمة وخصائص الخدمة

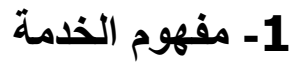

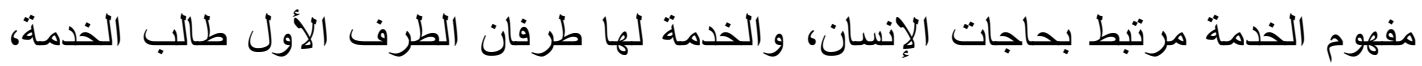

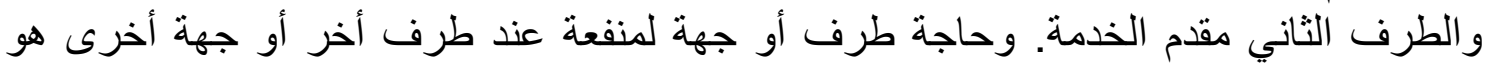

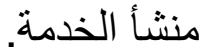

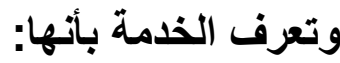

هى المنافع الغير ملموسة التي تقدمها المنظمة " مقدمة الخدمة " لعملائها سواء كانت حكومية أو غير حكومية . - افع الغير و إثباع حاجات طالبى الخدمة هو المسئولية الأساسية للمنظمة العامة ويتوقف نجاحها على إِثباع

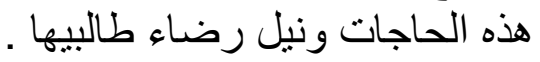

لذا فإن الأمر يتطلب توفير الإمكانيات وتأهيل الكوادر من أجل تقديم خدمة متميزة ترضى العملاء

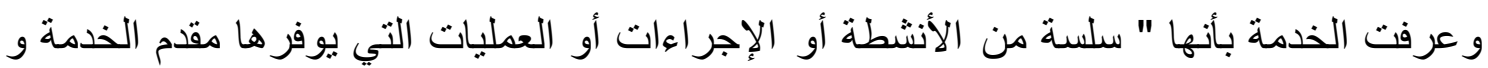

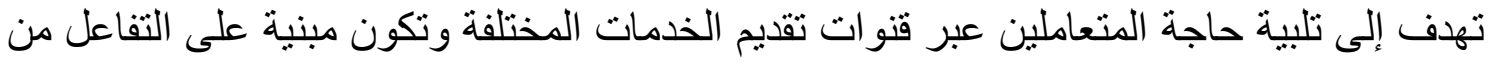

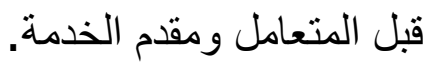

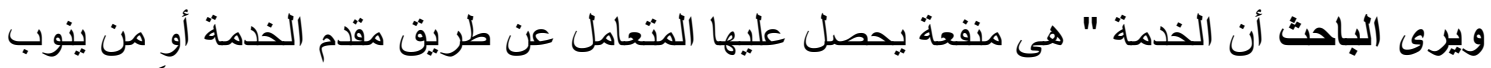
عنه وقد تكون إلزامية أو اختبارية ، وقد تكون مجانية أو بمقابل عبر إجراءات التهات غالباً مايحددها

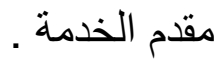

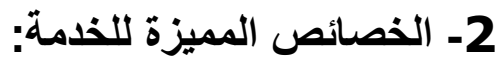

تتميز الخدمات بمجموعة من السمات والخصائص أهمها : 
- - الخدمات غير ملموسة وغير محسوسة، و لا بمكن إدر اكها ماديا.

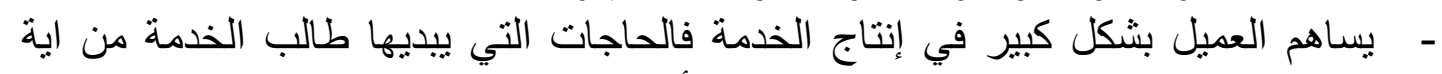

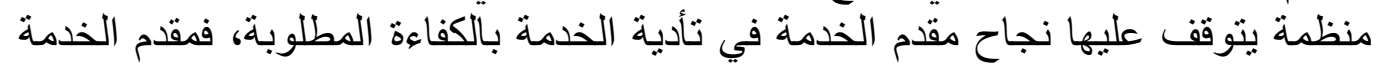

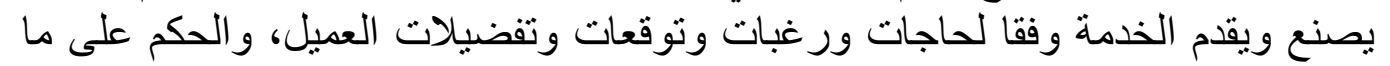
قدمه سيرتبط بما طلبه وتوقة وقعه العميل.

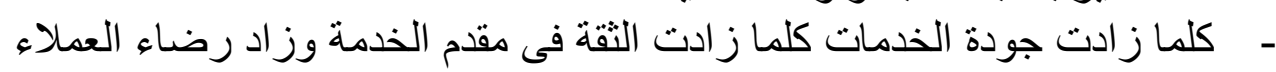

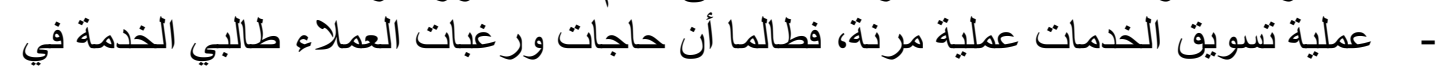

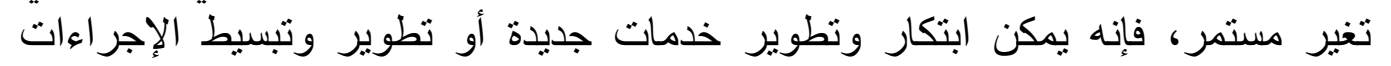

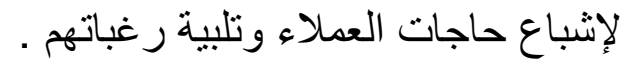
- تتغير نوعية الخدمات وفقا للإحتياجات و والعو امل الموسمية و غيرها.

\section{ثانياً : مفهوم الخدمات العامة :}

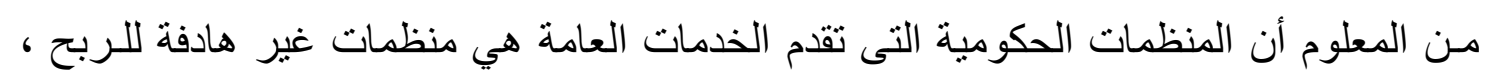

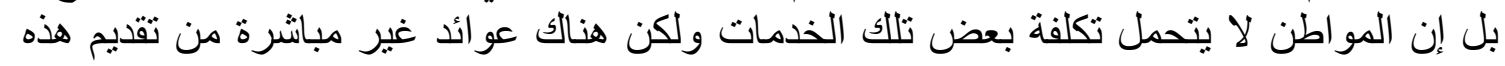

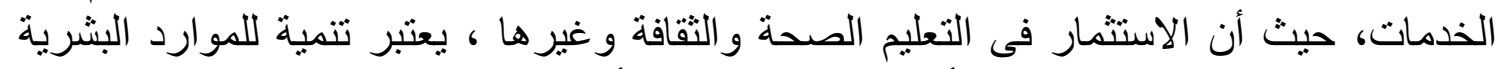

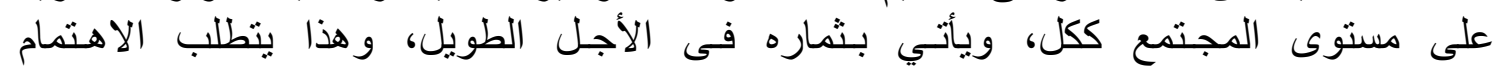

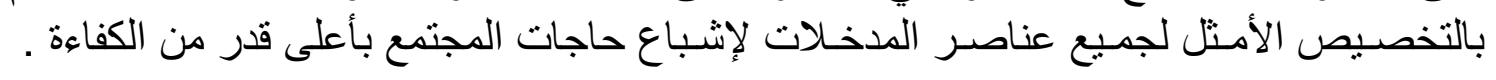

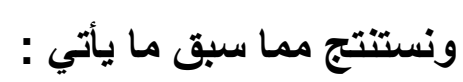

- ـ أن الخذمـات العامـة معنية بتلبية الحاجـات الأساســية لجميع المو اطنين و إثنباعها بدون

$$
\text { النظر إلى القدرات المالية . }
$$

- - تقديم الخدمات للمو اطنين هو مسئولية الدولة بالأساس وأحد أركان سيادتها .

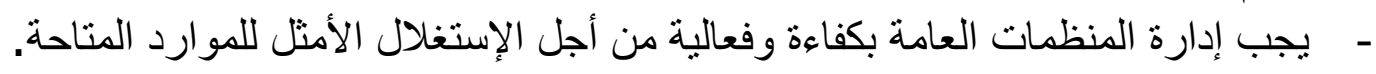

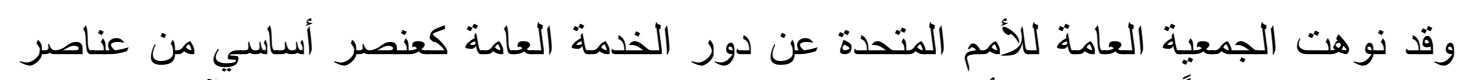

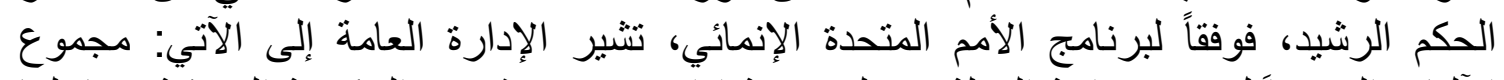

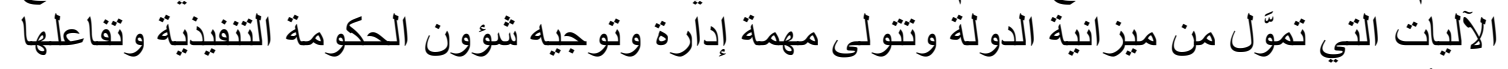

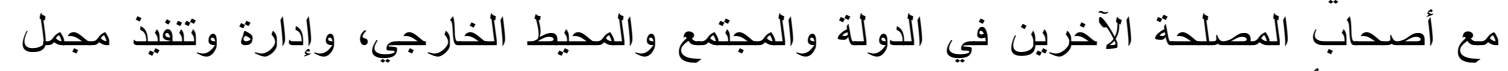

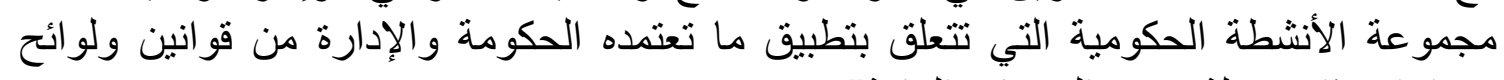

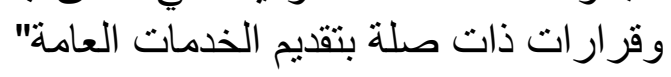

ويرتبط ذلك ارتباطاً وثثقاً بمفهوم إدارة القطاع العام التي تعرف وفقاً لتعريف الدفاهيم

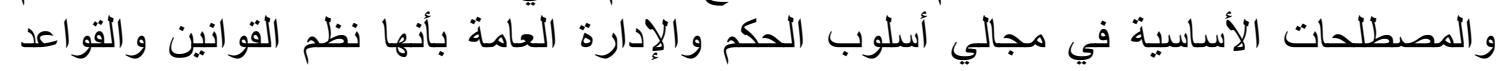

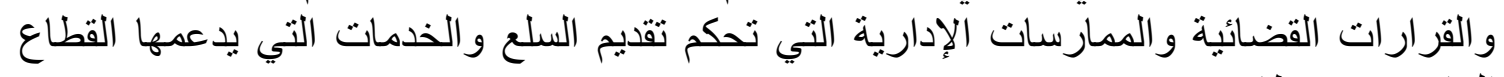
العام وتحدد نطاقه.

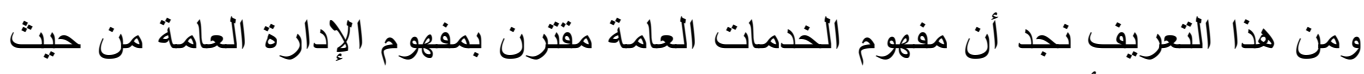

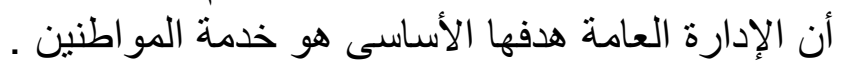




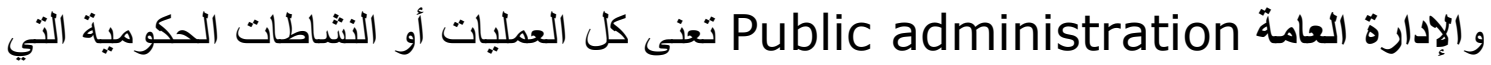

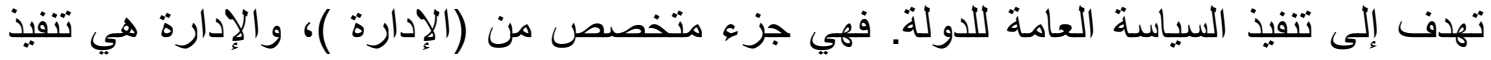

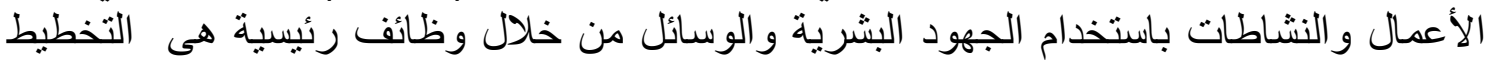
و التنظيم و التوجيه، و الرقابة ، من أجل تحقيق الأهداف بكفاية وفعالية.

و عندما تتعلق هذه الأعمال بتنفيذ السياسة العامة للدولة ومن خلال مؤسسات الدولة تسمى الإدارة

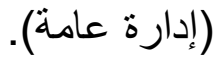

و هناك فرق بين الإدارة العامة وبين الحكومة، ويسهل معرفة الفرق بينهما إذا أخذنا فى الإعتبار

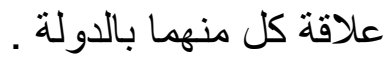

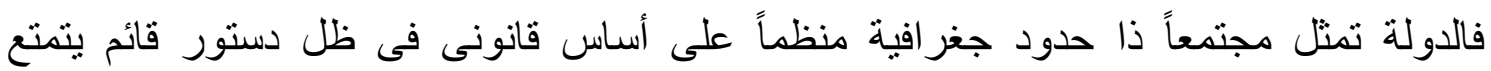

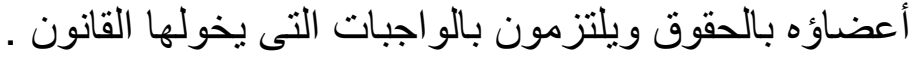
و الحكومة بمعناها العام هى التى تقرر السياسة فى هذا المجتمع وهى التى تضع اللو ائح والقو انين. أما الإدارة العامة تعنى مجموعة الأشخاص والأجهزة القائمين تحت إمرة الحكومة لأداء مهام

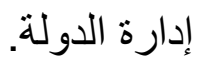

ويرى الباحث أن مفهوم الإدارة العامة يعنى " الأنشطة التي تمارسها الحكومة لتحقيق السياسة

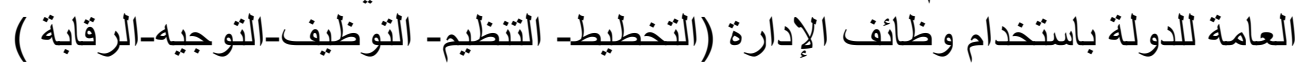

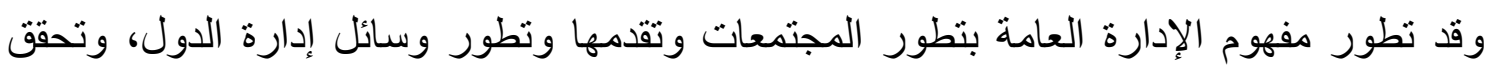

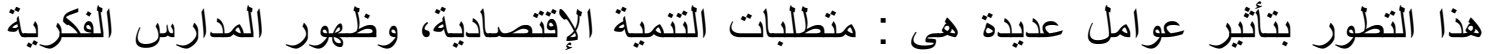

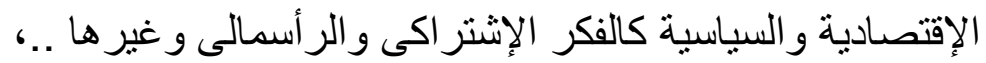

و وعم الإدارة العامة مثلكه مثل سائر العلوم الاجتماعية كالسياسة والاقتصاد والقانون العام والعام والمالية

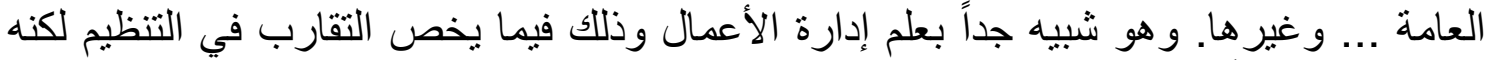

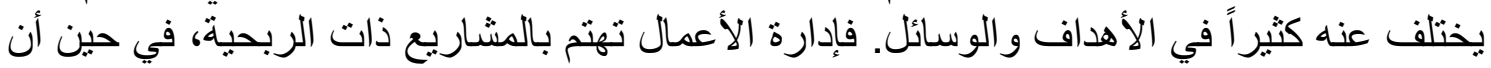
الإدارة العامة تهدف إلى تلبية حاجات المجتمع وتحقيق المصلحة العامة.

\section{وتختلف أهمية الإدارة العامة بحسب أنظمة الدول:}

فالدول الرأسمالية والتى تعتنق الدذهب الفردي، تعتبرتدخل الدولية عن طريق أجهزتها الإدارية

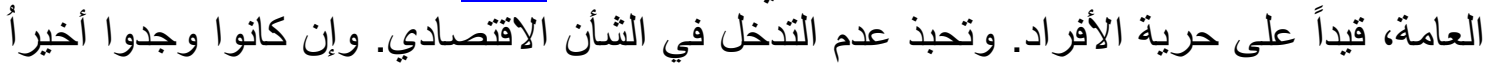

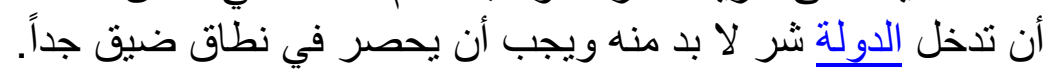

أما الدول الماركسية فتؤمن بتدخل الدولة إلى أقصى مدى، وهى ضد بد تماماً فكرة الملكية

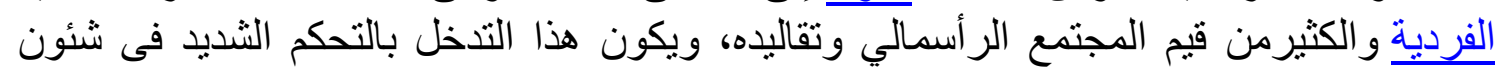
المجتمع عن طريق الأجهزة الإدارية العامة.

أما الدول الاشتر اكية فهى لا تلغى الطبقات تماماً ولا تأخذ بالمذهب الفردي بصورة كاملة، ولكن

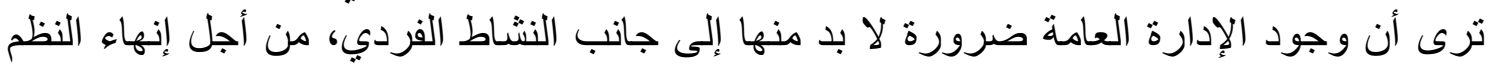
الإحتكارية ، و إثباع الحاجات العامة التي يعجز الأفراد عن إثباعها، عن طريق الأجهزة الدولة. 


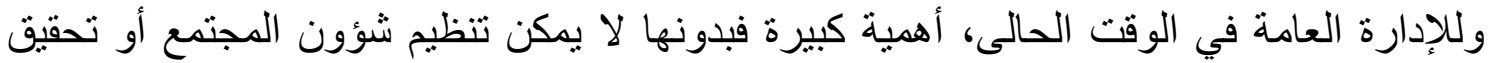

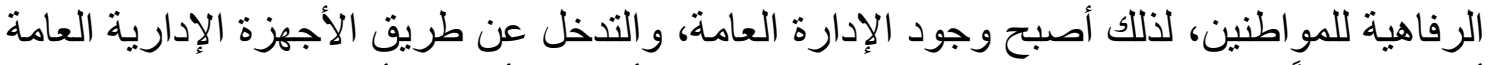

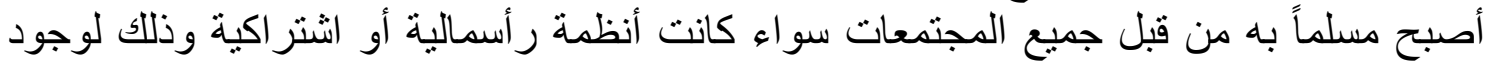

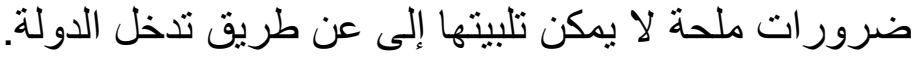

ثالثاً : والإدارة العامة لها وظائف مثل الوظائف الخاصة بإدارة الأعمال ويمكن أن تثمل

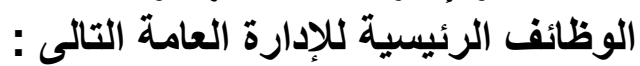

التخطيط :

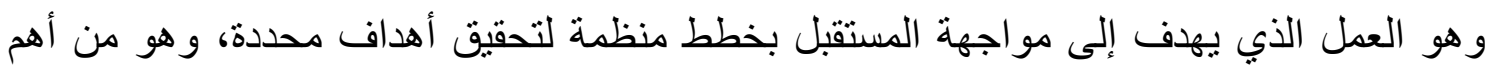

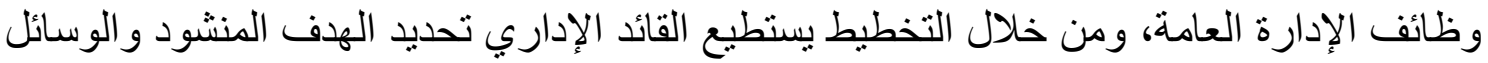

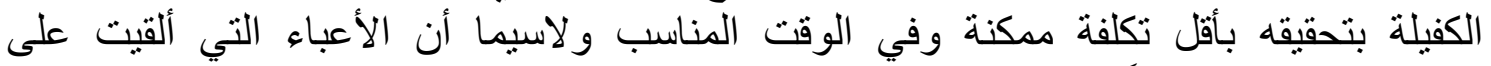

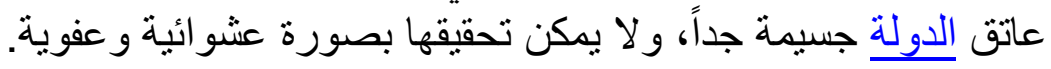

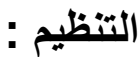

التنظيم وظيفة مهمة جداً للإدارة العامة فهو يحقق الوفر عن طريق استغلال الموارد البشرية و المادية وتضافر الجهود ومنع تبعثر ها.

القيادة : - 20 - n

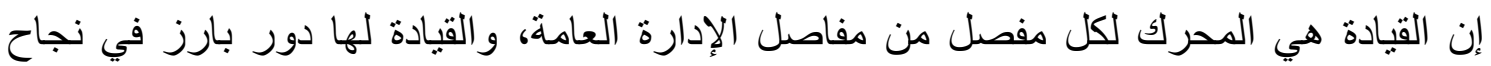

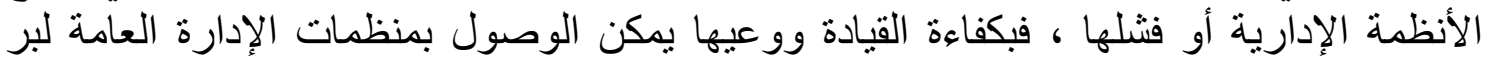

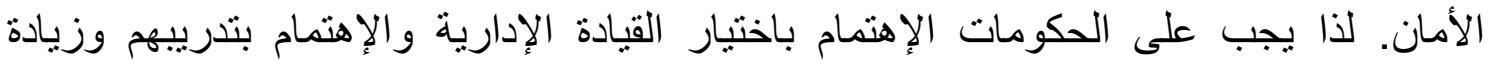
خبر اتهم وقدر اتهم من أجل ضمان استمر ار المنظمة في أداء مهمتها.

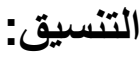

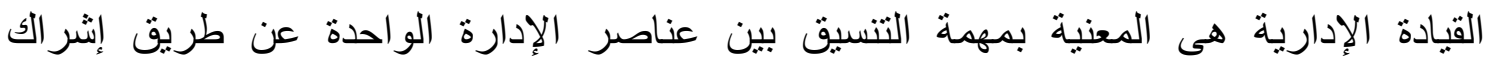

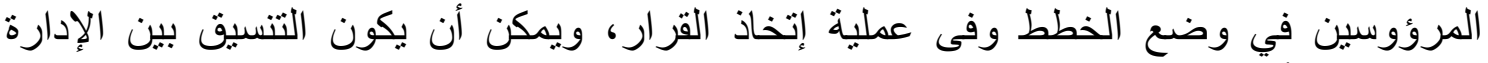

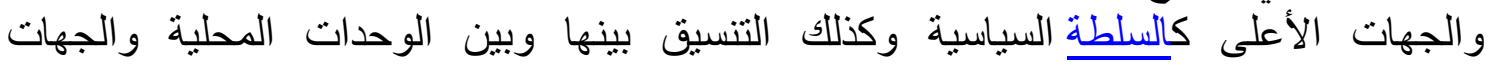

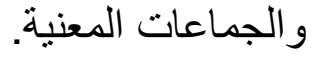

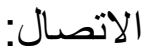

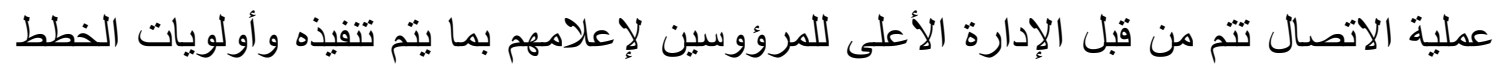

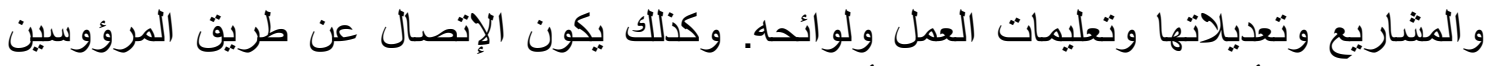

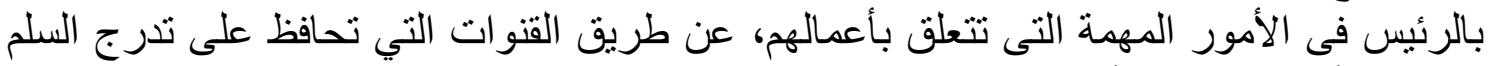

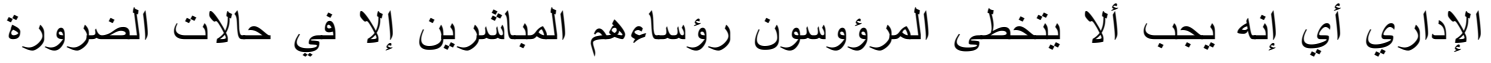

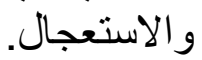


الرقابة جناح الإدارة الأخر بجانب التخطيط وهى تتعلق بكل وظائف الإدارة العامة وهى تنقل

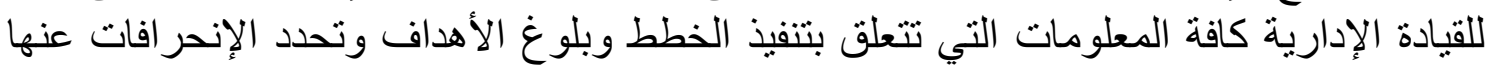
حتى يمكن معالجتها وتحدد كذللك المسئوليات.

وقد أحدثت الثورة الهائلة لتكنولوجيا المعلومات و الاتصالات وتطبيقاتها المتطورة و المتجددة و اقعاً

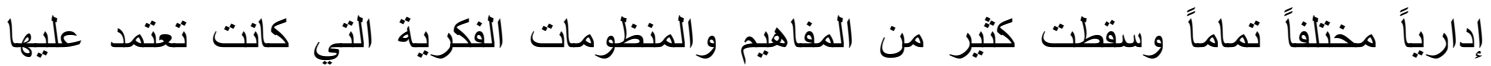

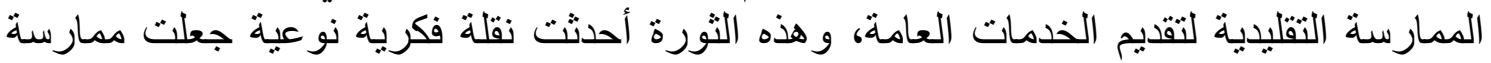
الإدارة العامة و أنظمتها مختلفة إختلاف كلى عن الممارسات التقليدية .

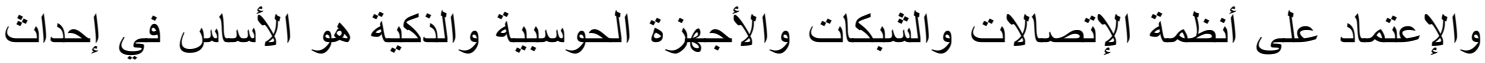

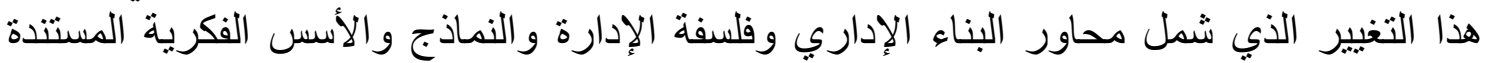
إليها ، و الهياكل التنظيمية و أنماط العلاقات و آليات العمل الإداري ـ الإدة والنيات

رابعاً : الفرق بين الإدارة العامة و إدارة الأعمال

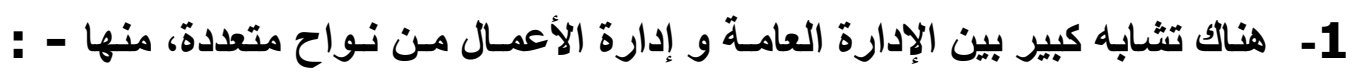

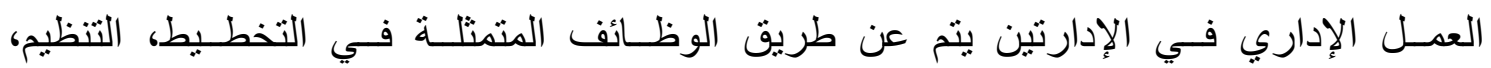

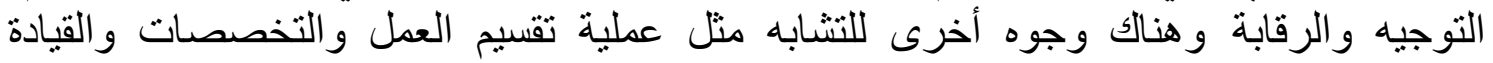

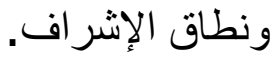

من أوجه التثابه أيضاً مبدأ اقتران السلطة بالمسؤولية فلا مسؤولية بدون صلاحية، ولا صلاحية بدون مسؤولية . ألمهن

و الإدارة العامة مثلها مثل إدارة الأعمال تهدف إلى تحقيق أهدافها بأقل تكلفة و أقصر وقت و أفضـل

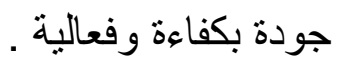

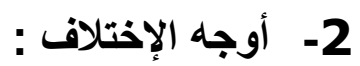

تختلف الإدارة العامة عن الإدارة الخاصة ( إدارة الأعمال) في عدة أمور ، أهمها ما يلي:

- - تقوم الإدارة العامة بترجمة السياسة العامة للدولة إلى أعمال تنفيذية، وتأديتها في إطار

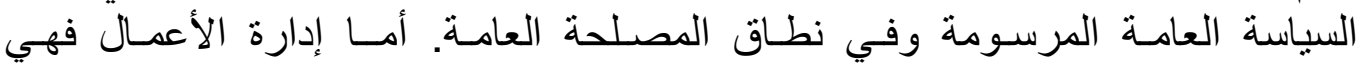

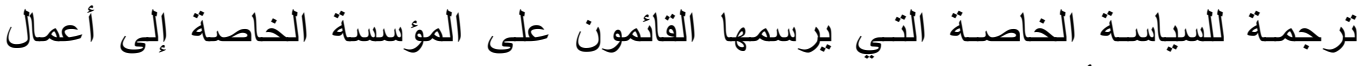

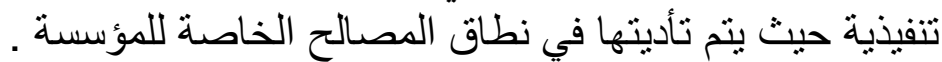

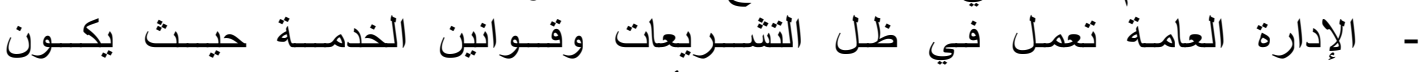

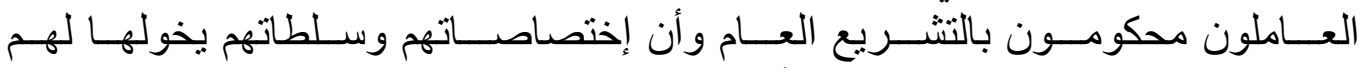

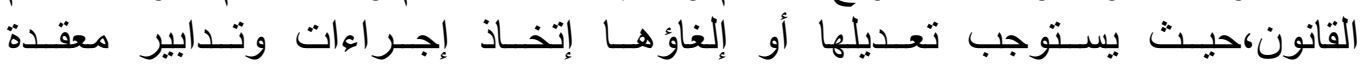

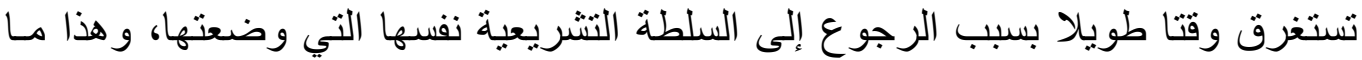

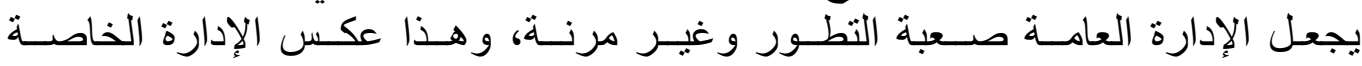

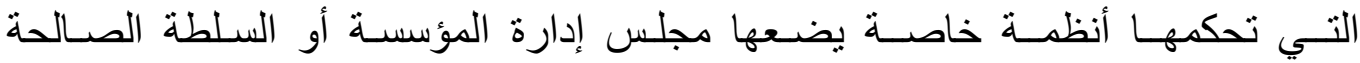

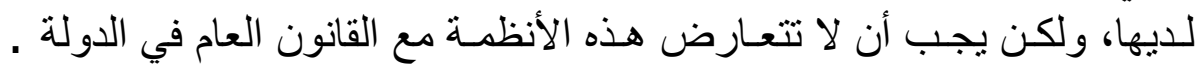




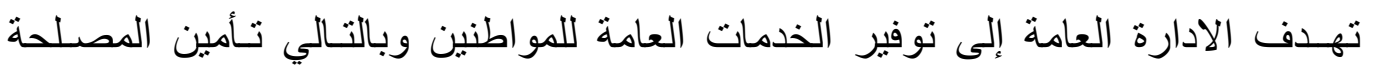

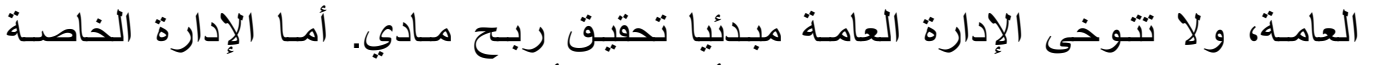

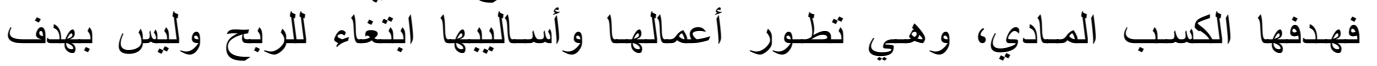

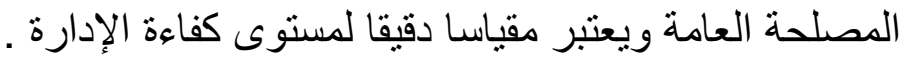

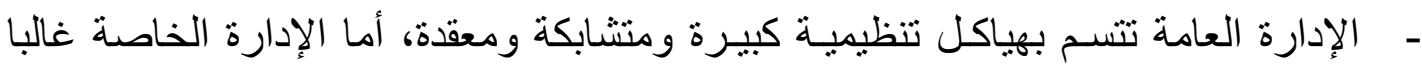

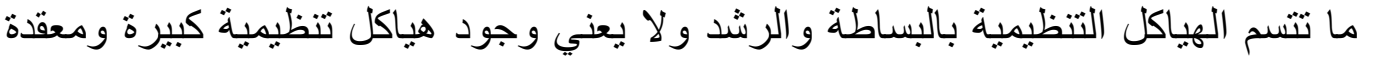

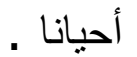

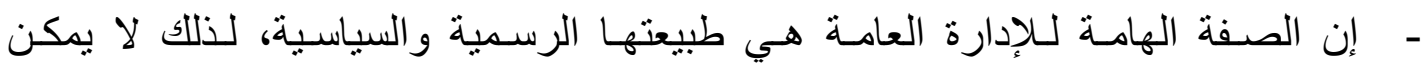

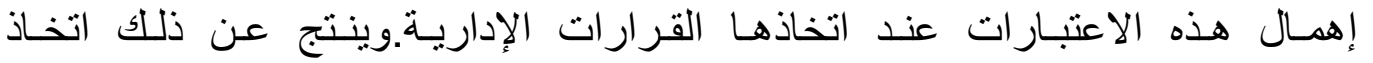

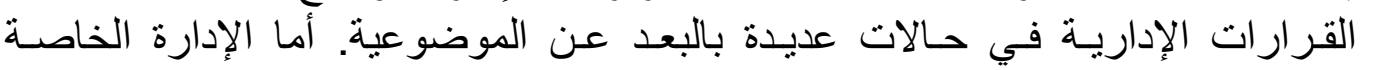

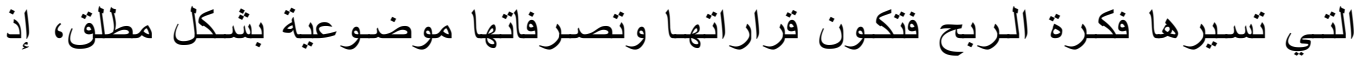

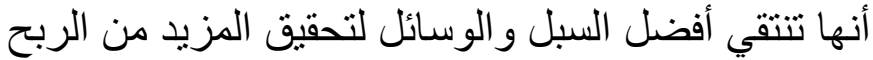

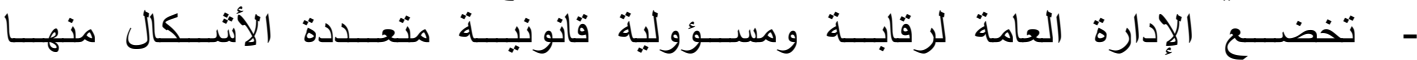

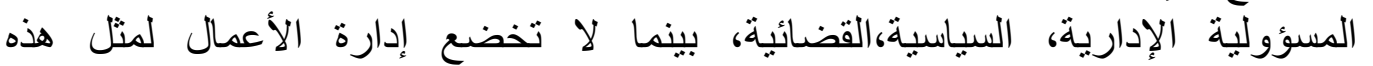

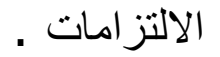
ـ يتسم عمل المؤسسات الحكومية بالاحتكار ، بينما تسود المنافسة عمل المؤسسات الخاصة

خامساً : ملامح النموذج التقليدي في الإدارة العامة ودوافع التغيير:

يتفق معظم الباحثين في حقل الإدارة العامة أن تناول موضوع الإصداحات في الإدارة العامة جاء

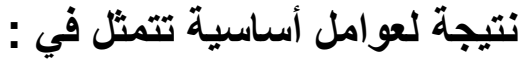
- الضغوطات المالية الناتجة عن تزايد النفقات العامة .

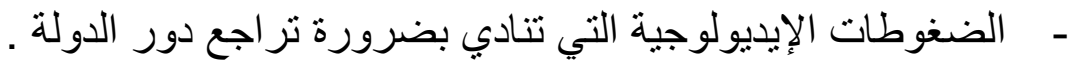

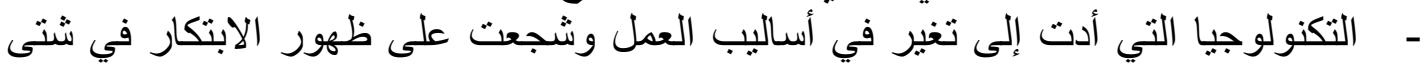
المجالات .

- ضغط جمهور المواطنين لإضفاء الفعالية على أداء الحكومات وتحسين الخدمة المقدمة .

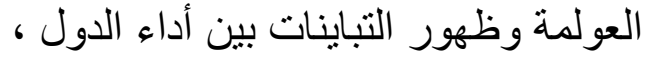

وهناك منظوران لتقيبم الإدراة العامة التقليدية : 1-المنظور الاقتصادي : 1

حيث يتضمن هذا العنصر أزمة الإدارة العامة من منظور الاقتصاد الكلي أو المؤشرات الكلية

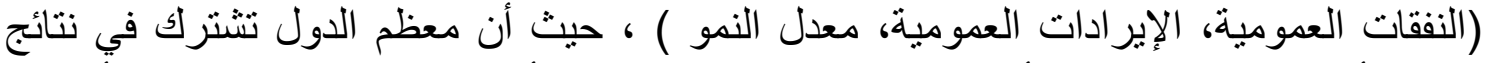

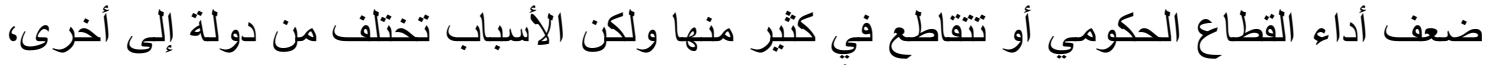

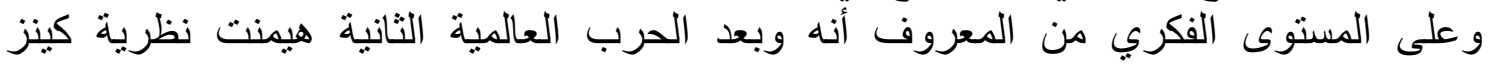
و أفكار ها على الاقتصاد وهذا من خلال الدور الإيجابي للاولة في التتمية الاجتماعية والاقتصـادية، 
حيث كانت القاعدة الأساسية التي تستند إليها هذه الأفكار هي أن زيادة التدخل الحكومي ينتج نمو

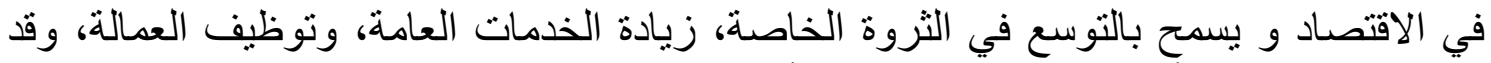

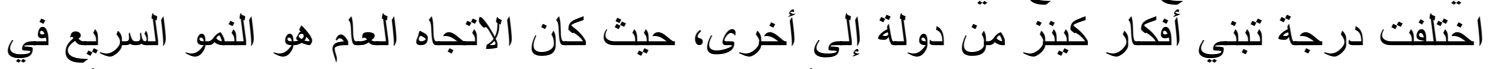

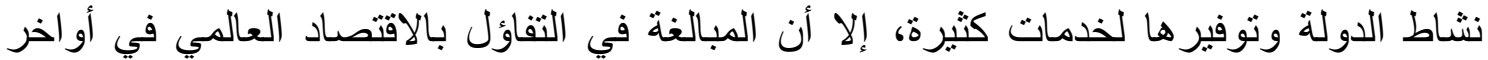

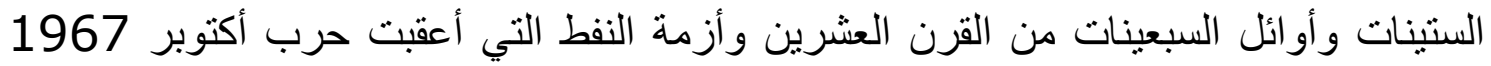

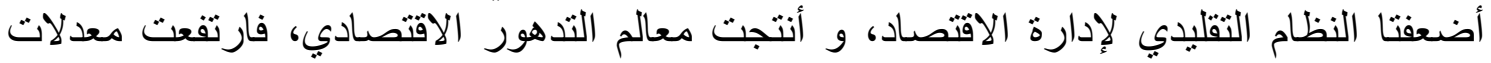

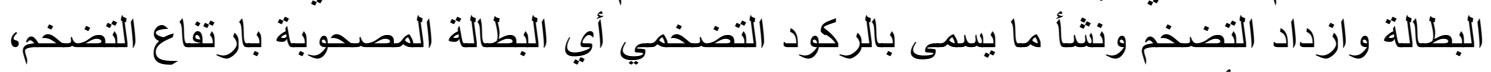

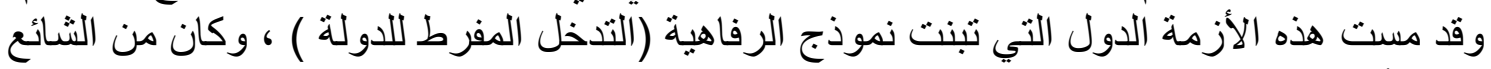

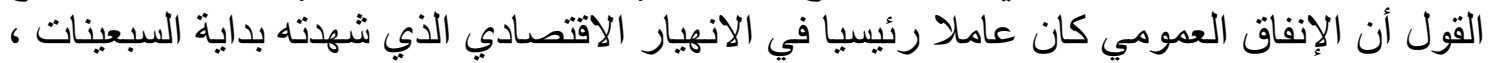

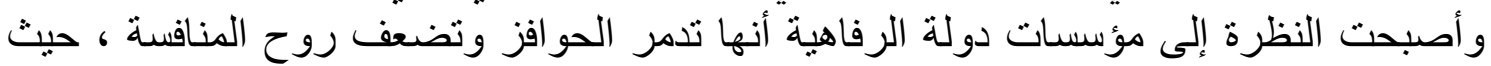

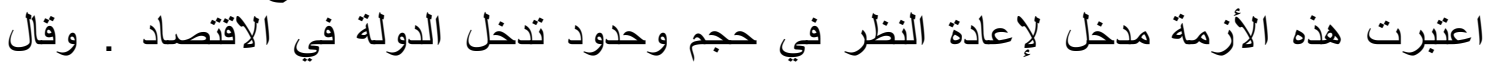

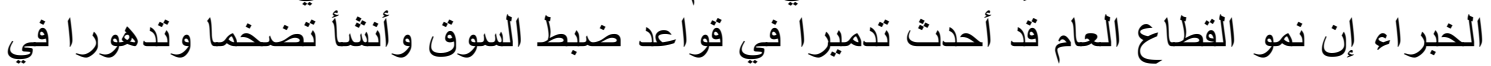

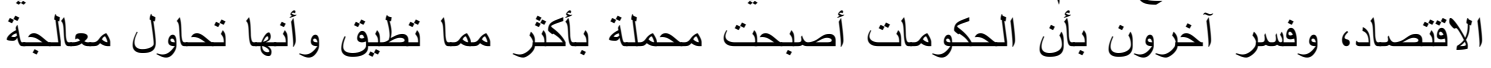

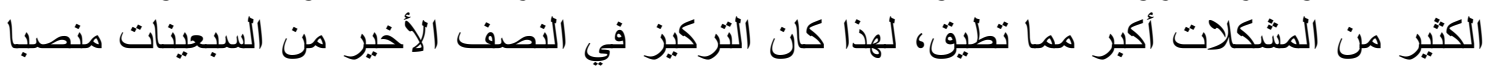
على التقليل من الإنفاق الحكومي أو على الأقل على التخفيف من معدل نموه الذي الذي كان سائدا

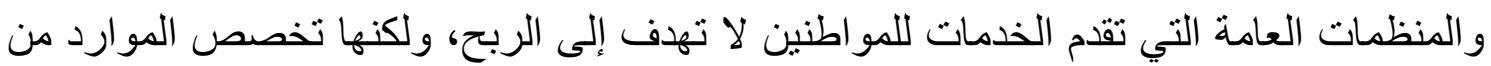
أجل إثباع الحاجات الضرورية للمواطنين دون النظر إلى قدرتهم المادية.

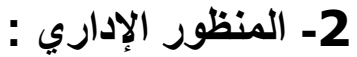

هنا يتعلق الأمر بالمشاكل التي واجهت المؤسسات والهيئات العامة في طريقة إدارتها و انعكاسه على مستوى أدائها.

\section{وتتمثل هذه التعقيدات الإدارية فى :}

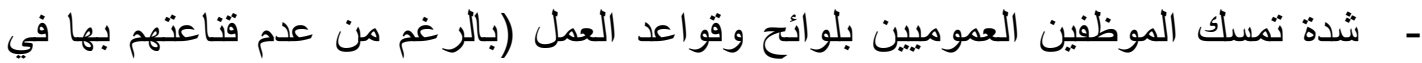

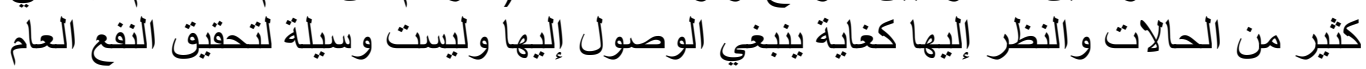

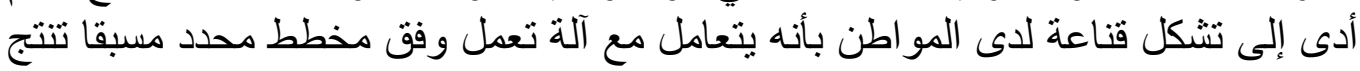

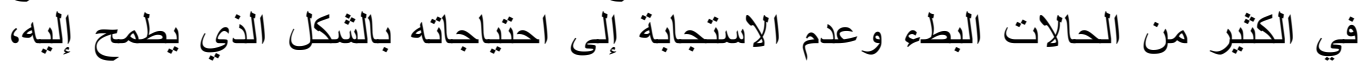

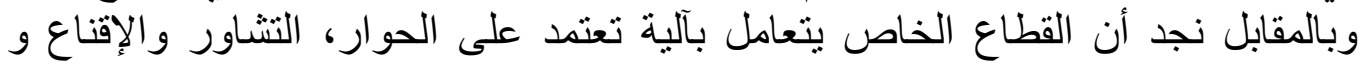

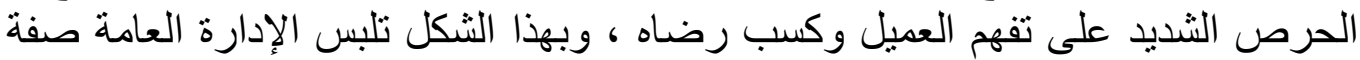

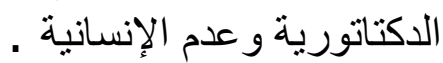

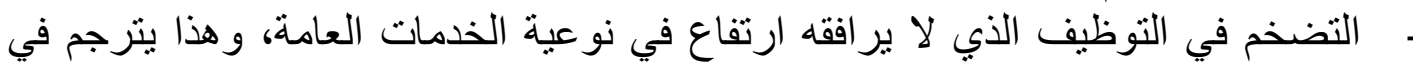

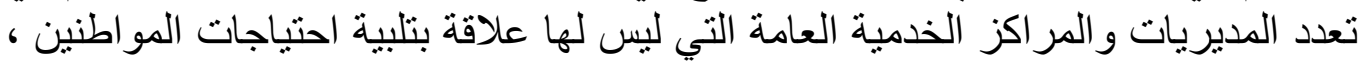

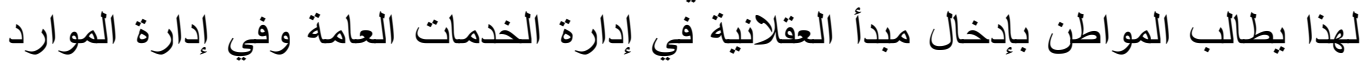

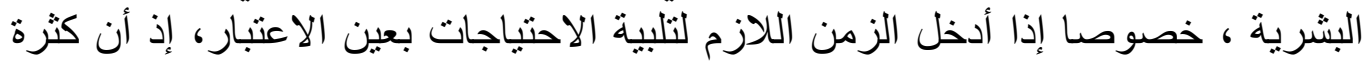

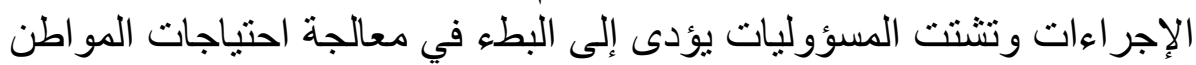

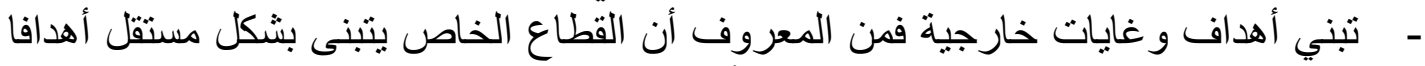

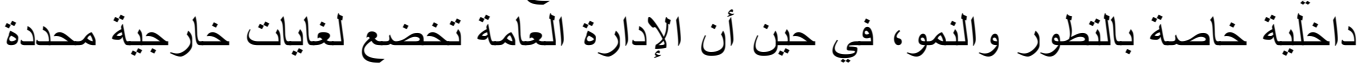


في صورة الصالح العام، ومنه استراتيجية الإدارة العامة مقيدة بالأهداف الخارجية من

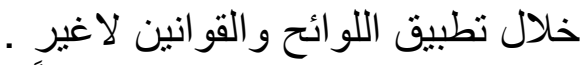

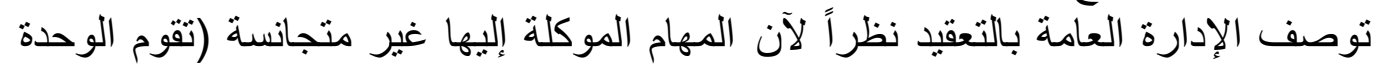

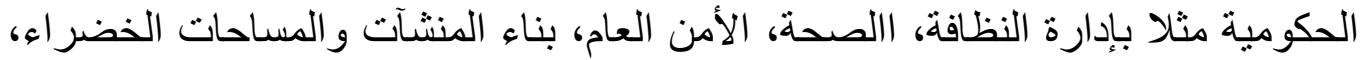

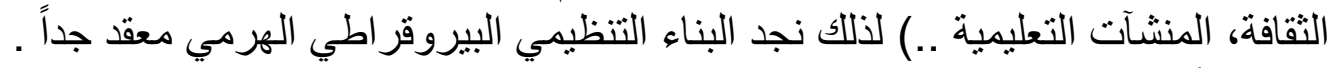

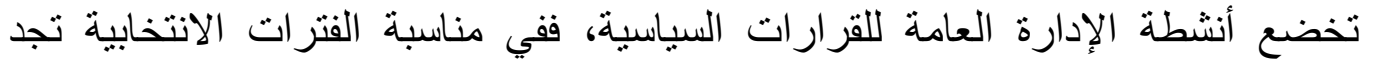

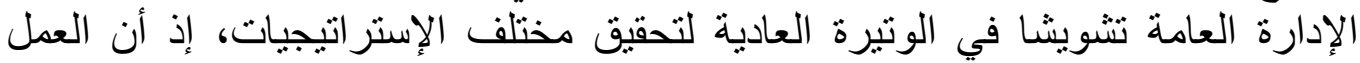

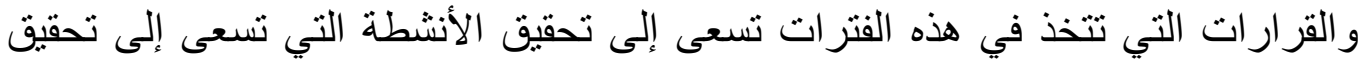

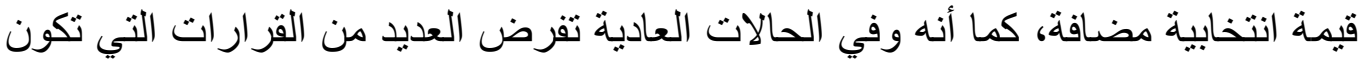

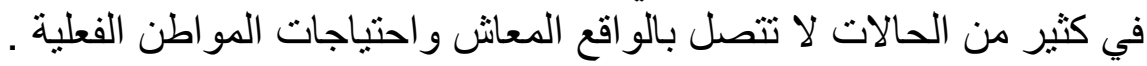

سادساً : الإدارة العامة العديثة :

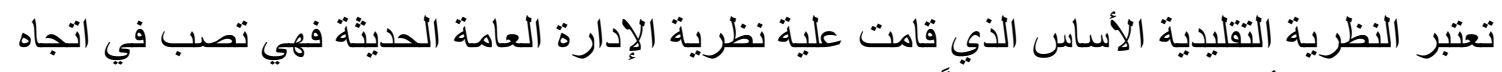

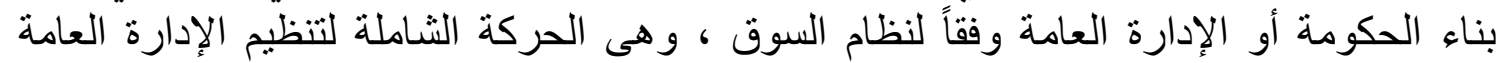

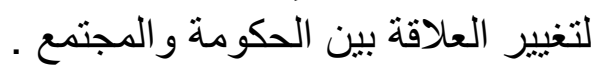

\section{1- 1 مفهوم ونثأة الإدارة العامة الحليثة}

لقد تزايدت مشاريع الإصلاح الإداري في سنوات السبعينيات خاصة بعد الأزمة البترولية وما

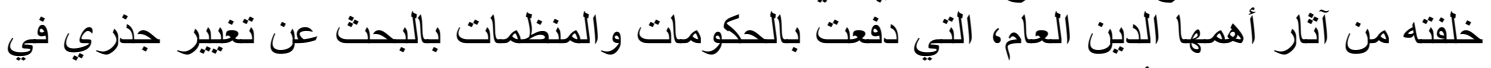

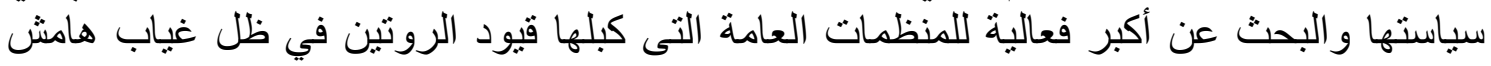
الحرية لدى الموظف العام الذي ساهم في كبح الإبداع و التجديد

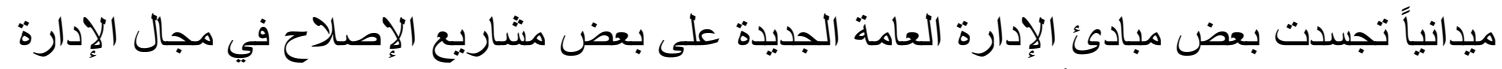

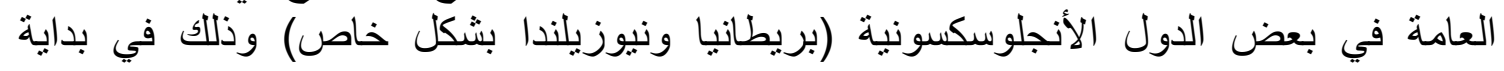

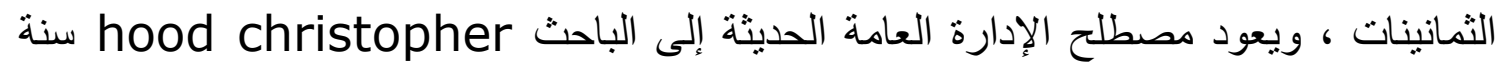

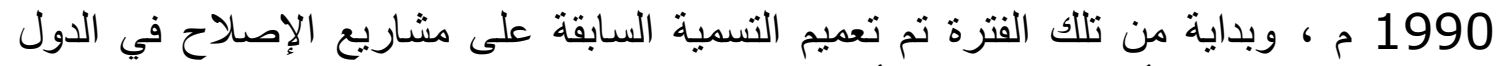

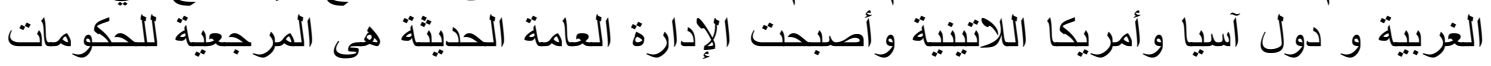

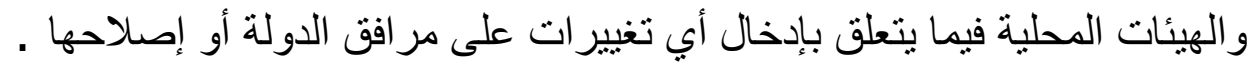

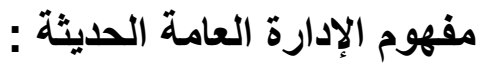

تعبر الإدارة العامة الحديثة عن تنفيذ مجموعة من القرارات الحكومية التي قادت إلى إلى تغيير

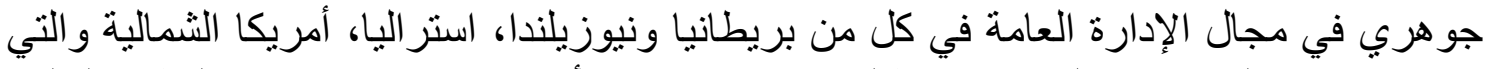

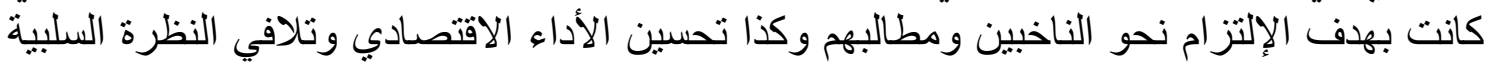

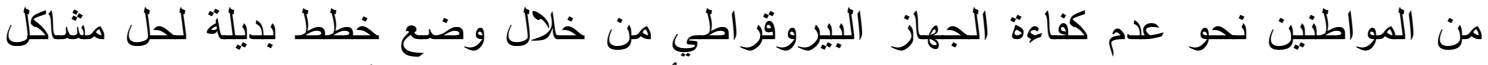

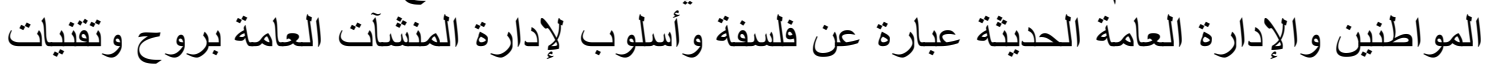

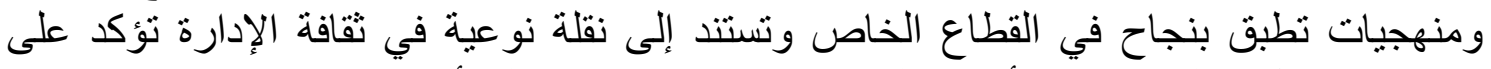

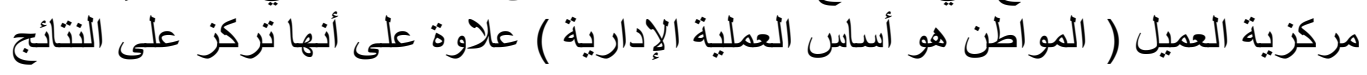




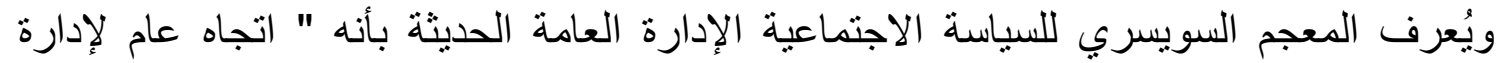

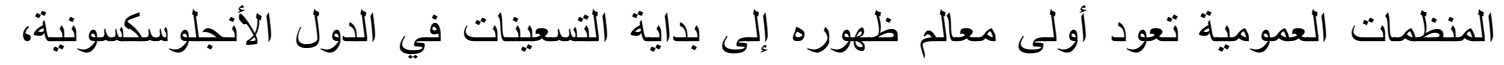

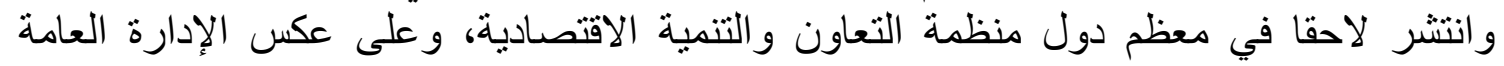

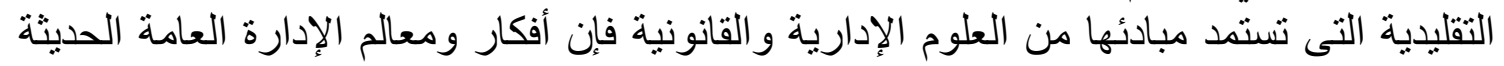

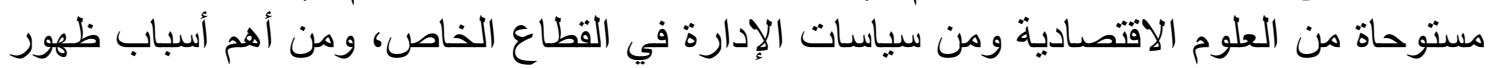

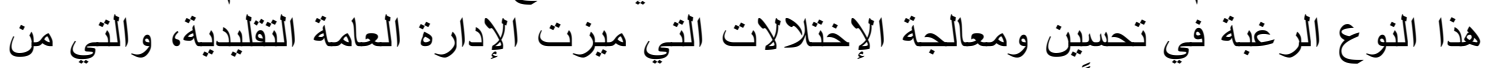

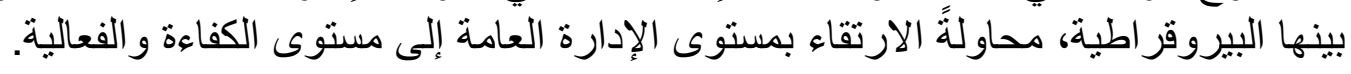

\section{وترتبط كفاءة إدارة الخدمة العامة بالعديد من الجوانب :}

$$
\begin{aligned}
& \text { - - - تو افقها مع البيئة الخارجية للمنظمة. }
\end{aligned}
$$

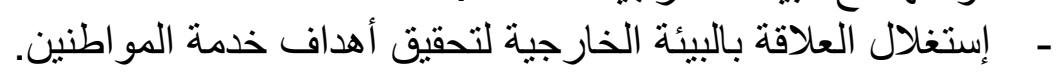

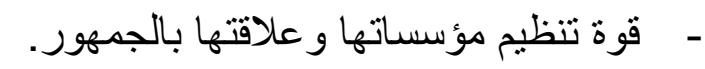

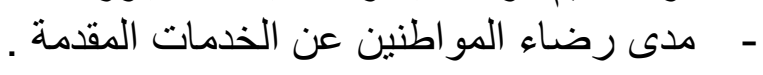

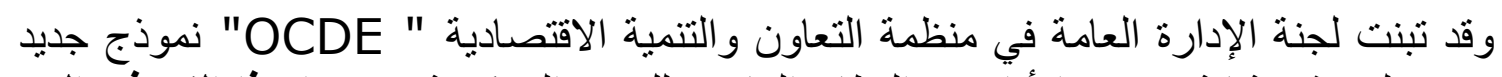

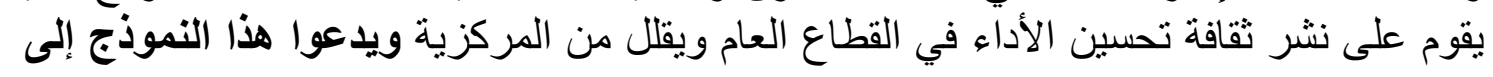

-

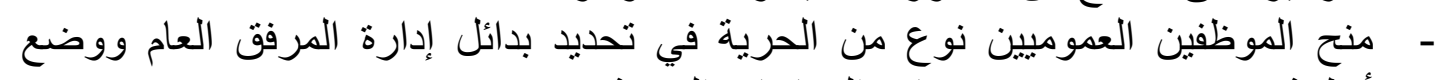

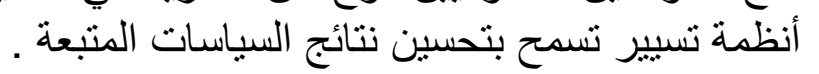

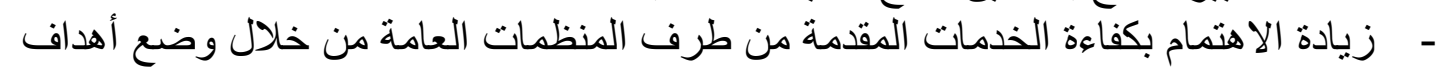

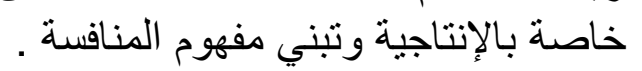

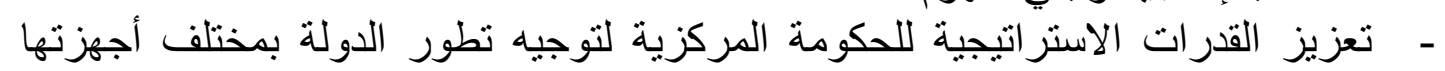

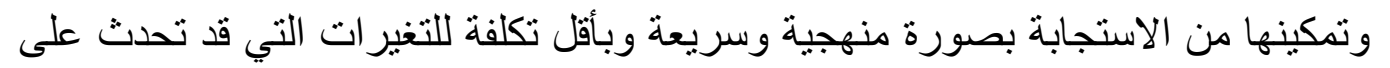

$$
\text { مختلف المستويات . من الانيجات }
$$

\section{2- الإلتزامات الجديدة للإدارة العامة في ظل تطبيق الإتجاه الحديث :}

إن انتقال الإدارة العامة من الإدارة البيروقراطية إلى الإدارة العامة الحديثة سوف يغير من لإدئ وضعية الإدارة العامة بإعطائها صبغة جديدة الإدان التضمن:

1-2 التكيف المستمر مع المتغيرات البيئية : من خلال رصد مختلف هذه التغيرات ومتابعتها

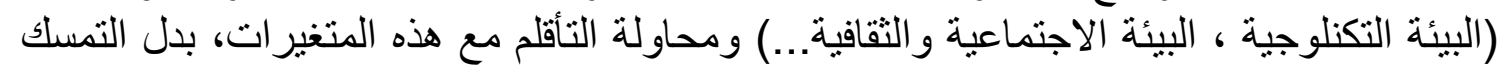

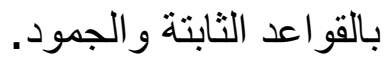

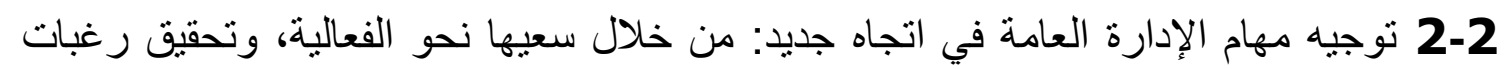

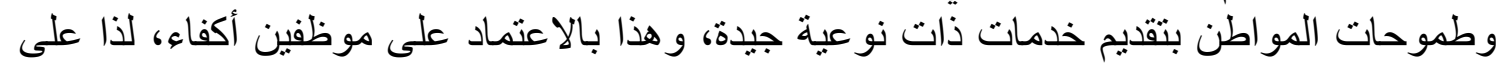

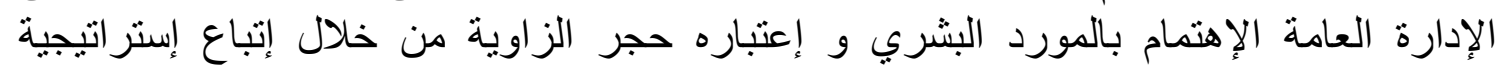

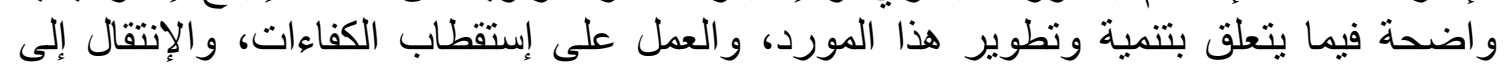
معاملة الموظف على أساس الأداء وليس على على أساس الخبرة فقط ولئ . 
3-2 إثعار الموظفين العموميين بالمسؤولية : لأن الإشعار بالمسؤولية يحفز الموظف العمومي

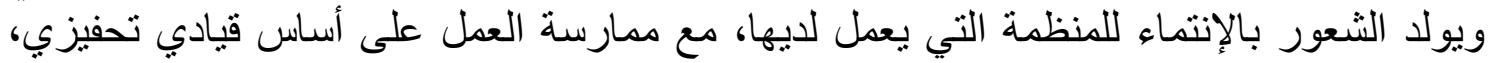

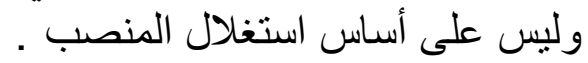

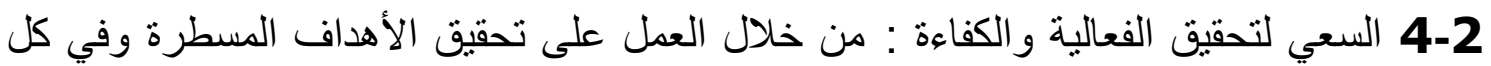
المستويات، كما يجب أن تعمل الإدارة على الاقتصاد في الموارد العاد والعمل على الإلى استغلالها

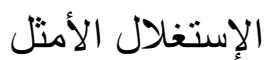

5-2 التقرب من المواطن : و هذا من أجل استجابة أفضل لمتطلباته و احتباجاته ، كما يجب

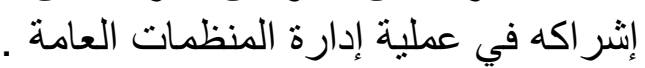

6-2 السرعة في تقديم الخدمات : لأن الوقت عامل مهم في الحكم على أداء الإدارة العامة،

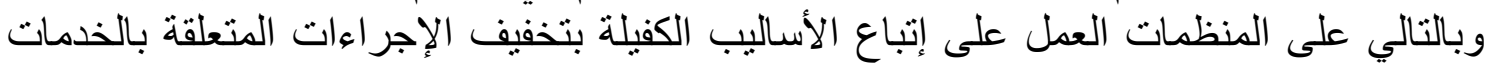
المقدمة.

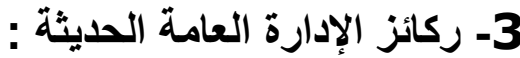

أجمع المختصين والباحثين في مجال الإدارة العامة الحديثة إلى أن هناك ركائز بني عليها هذا

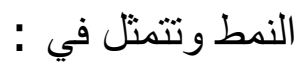

\section{1-3 تغير الاستراتيجية الحكومية:}

\section{الإدارة العامة الجديدة تثمل تغيير في البناء الهيكلي للحكومة كما يلي:}

- إعادة هيكلة الإدارات ( تبسيط الهياكل الإدارية، من خلال خلق وحدات بسيطة متجانسة

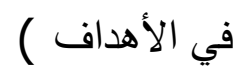

$$
\begin{aligned}
& \text { - اللامركزية في السلطة والمسؤولية (لتحقيق الاستجابة السريعة) }
\end{aligned}
$$

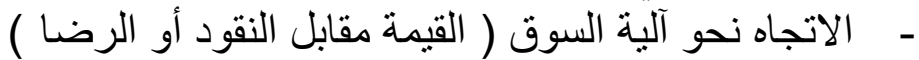

-

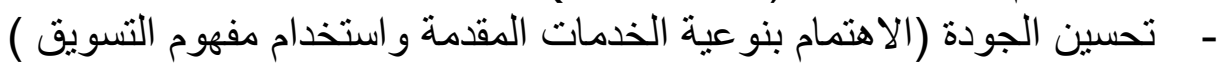

$$
\text { - }
$$

- - ميثاق للمو اطن (إلنزام من طرف الإدارة بتحقيق خدمات تستجيب لتطلعات المو اطنين)

\section{2-3 تغيير النظم الإدارية :

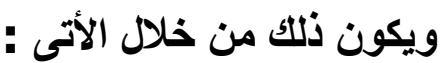

- إعتناق الفكر الإدارى للقطاع الخاص من خلال التميز، إدارة الجودة الثاملة، الحوافز،

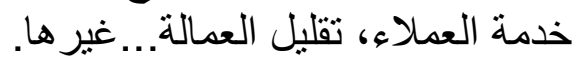
-

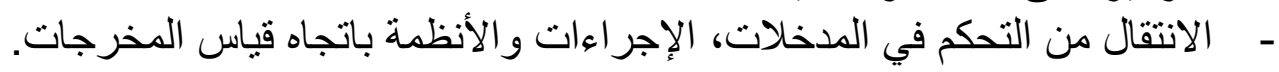

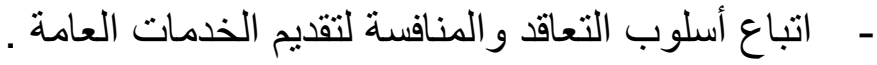


3-3 تخفيض السيطرة الحكومية :

ويثمل تخفيض السيطرة الحكومية :

$$
\text { - }
$$

و هنالك بعض المشاريع الريادية التى يمكن أن تتبناها الإدارة العامة الحديثة لتساهم فى عملية التنمية الثناملة والتحول الجذرى فى مختلف قطاعات الدولة منها على سبيل المثثال :

$$
\text { - } \begin{array}{r}
\text { - } \\
\text { - }
\end{array}
$$

سابعاً : علاقة الخدمات العامة بنظم المعلومات والإتصالات :

1 - 1- استيعاب نظم المطلومات

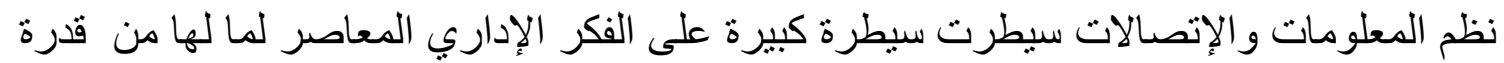

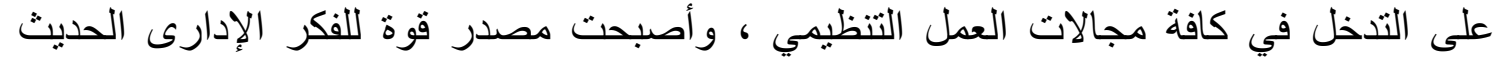

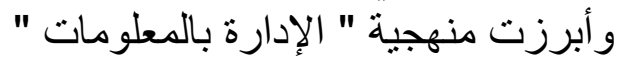

و التزايد المستمر فى أهمية نظم المعلومات يرجع إلى ظهور ثلاثة متغيرات عالمية باتت تحكم على كافة المنظمات العامة و هى :

1-1

تزامنت العولمة مع ثورة الاتصالات وتكنولوجيا المعلومات وهو ما أدى إلى تدفق كميات هائلة

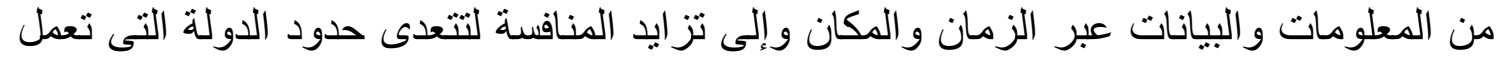

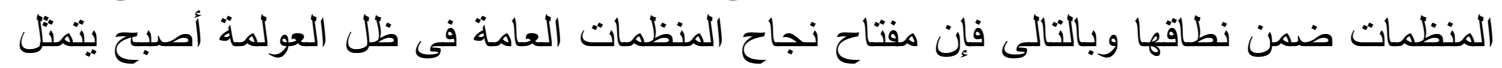

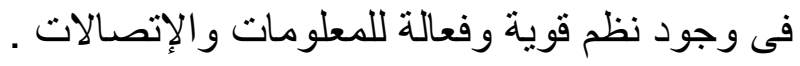

2-1 التحول إلى الاقتصاديات الصناعية

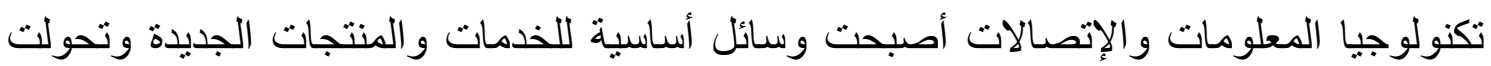

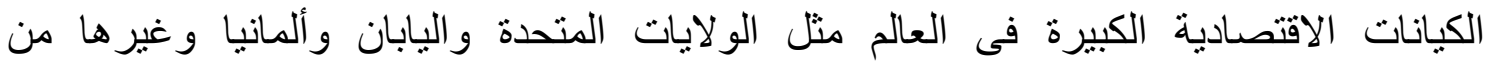

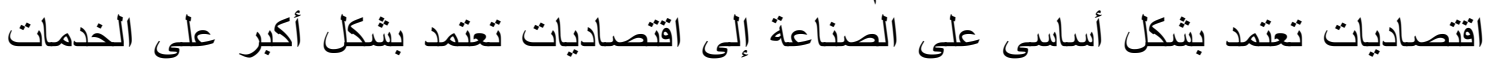

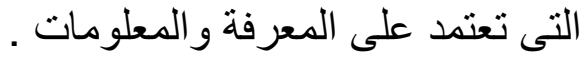




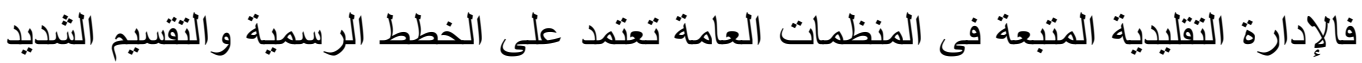

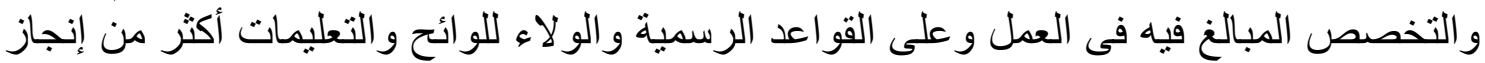
العمل و المركزية الثنديدة فى إتخاذ القرار اتعل الإدارية.

ولكن الإداراة الحديثة لمنظمات الإدارة العامة اليوم تعتمد على تكنولوجيا المعلومات لتوفي لتخطيط

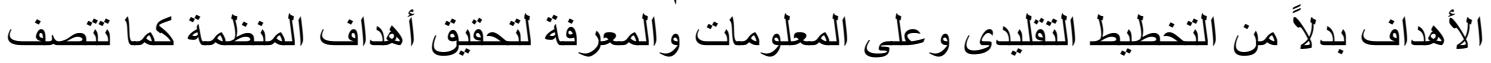

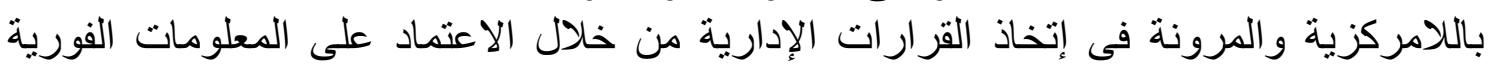

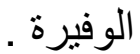

\section{ومن مظاهر استخذام نظم المعلومات فى الإدارة العامة مايلى :}

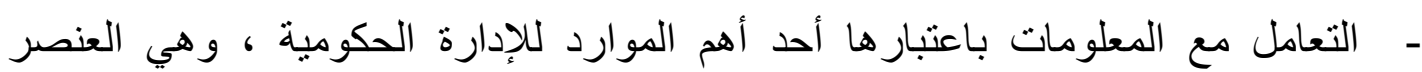

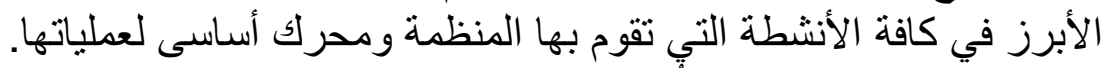

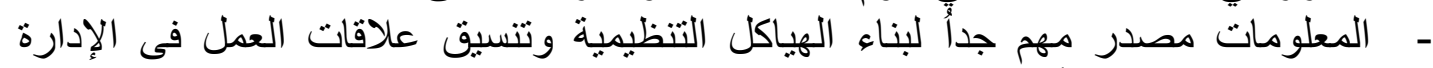

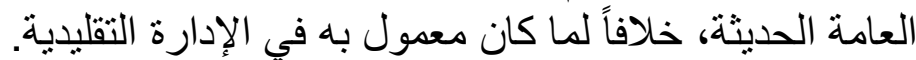

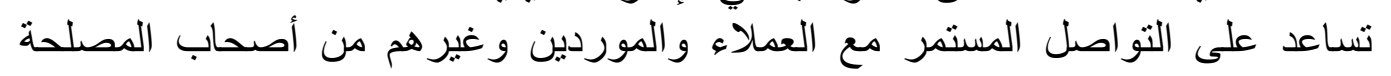

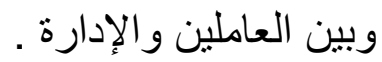

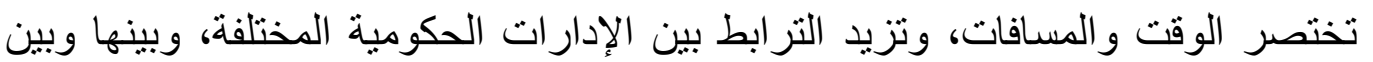

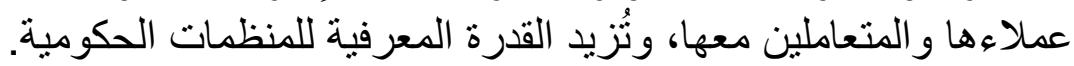

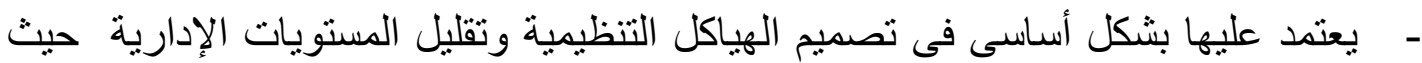

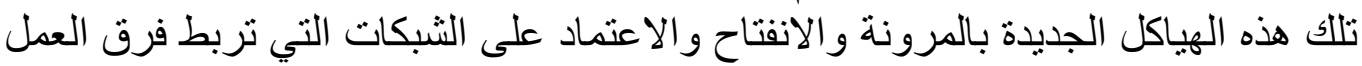

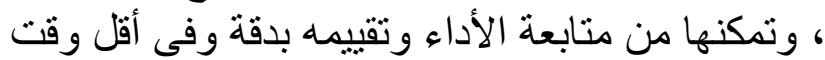

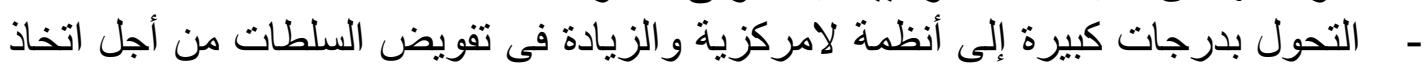
القرار ات بسر عة وحرية أكبر.

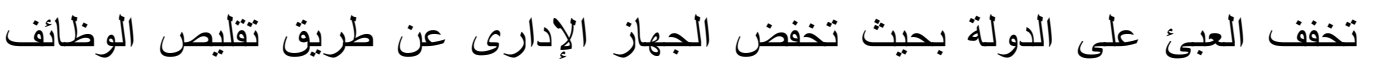

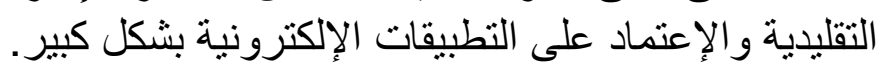

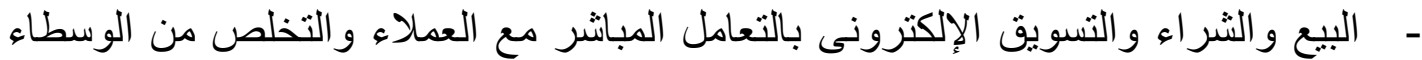

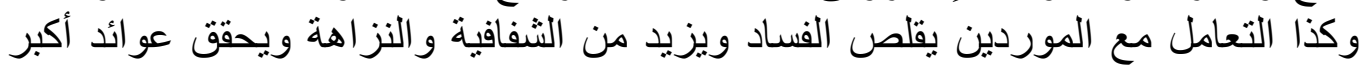

$$
\text { بكثير . ب. }
$$

\section{2- دور نظم المعلومات فى تطوير الإدارة العامة :}

الفكر الإدارى الحديث يتبنى إدارة نظم المعلومات حيث أن التطور الهائل فى تكنولوجيا

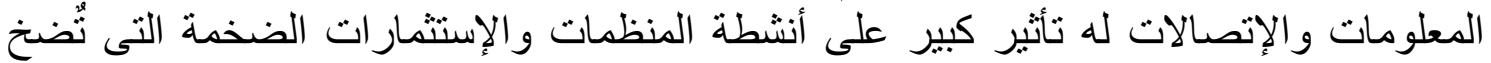

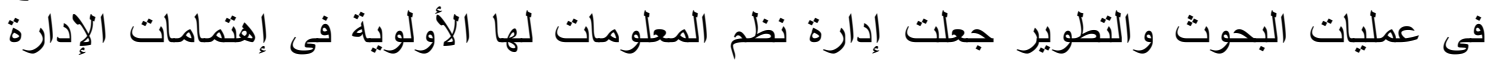

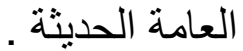

كما أن الفكر الإدارى الحديث بستغل تأثير تكنولوجيا المعلومات والإتصالات فى عمل المنظمات

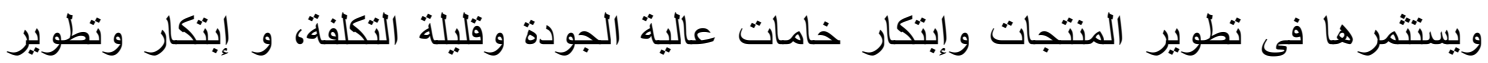
أليات ونظم للإنتاج تتسم بالوفرة والنّات وإنتاع الجودة وقلة التكلفة . 
وفى مجال الخدمات العامة تستغل الإدارة الحديثة وسائل التقنية فى التحرر من قيود الزمان التئن

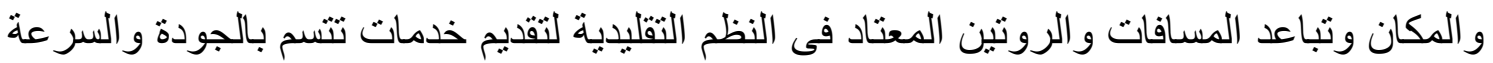
وقلة التكلفة.

ويعنى الفكر الإدارى الحديث فى ظل تقنية المعلومات والإتصالات بالمواردارد البشرية وتدريبها

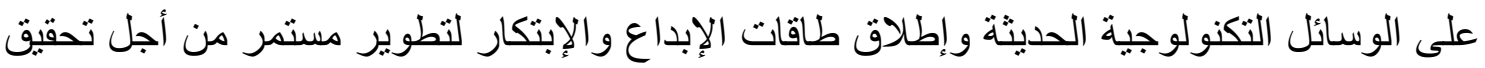
النتائج المستهدفة بكفاءة وفعالية.

\section{3- التغيرات الأساسية التي يحدثها تطبيق تكنولوجيا المعلومات في مفهوم الإدارة والعمل:}

- - تغيير أساليب العمل، فاستخدام التكنولوجيا الحديثة تسمح بالعمل عن بعد وكنلك بلك إعطاء

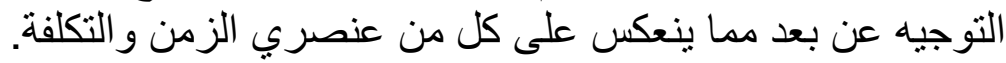

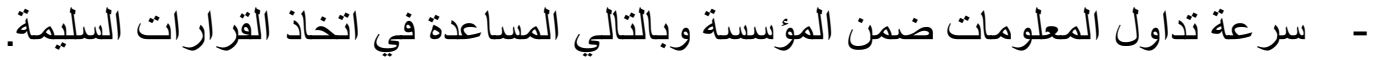

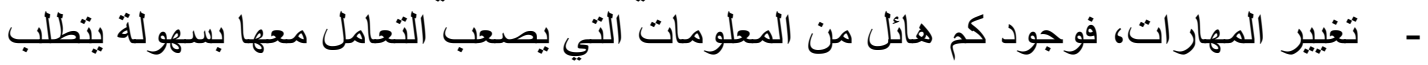

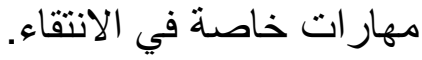

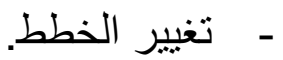

- - تحرير العنصر البشري من قيود الأعمال الروتينية ومنه إلى الأعمال الإبداعية والفكرية.

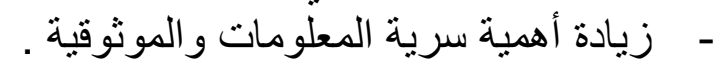

\section{4- التحول إلى التسويق والمعاملات الإكترونية :}

قوى السوق هى المحرك الرئيسى لأنشطة المنظمات فنشأة المنظمات و إستمر ارها وكذلك فثلها و إنهيار ها يحددها جميعاً قوى السوق الرئى لالنطي

و الإدارة الحديثة تبدأ بالسوق وتنتهى بالسوق ورضاء العملاء هو الهذف الرئيسى لهذه المنظمات .

وقد ساهمت تكنولوجيا المعلومات والإتصالات بشكل كبير فى عملية التفاعل بين المنظمة

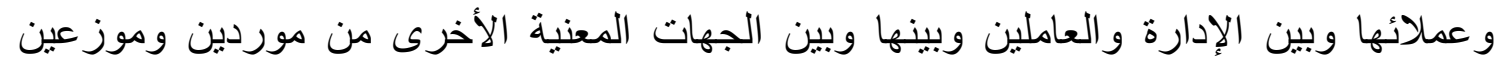

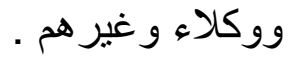

و أصبحت المعاملات الإلكترونية عبر الثبكة الدولية للمعلومات والثبكات الأخرى هى الوسيلة

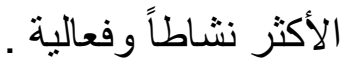

وقد كان لهذا التحول الكبير للنظم الألية اثر بالغ على الهياكل الإدارية للمنظمات ونظم العمل بها

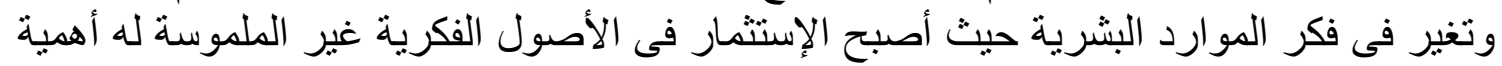

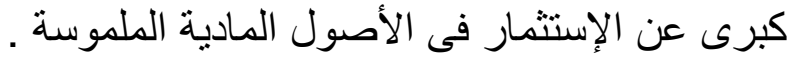




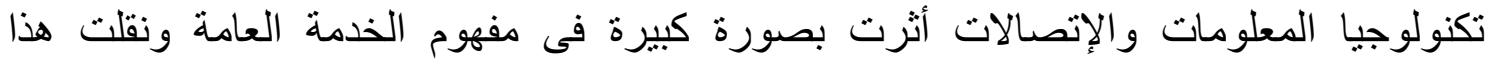

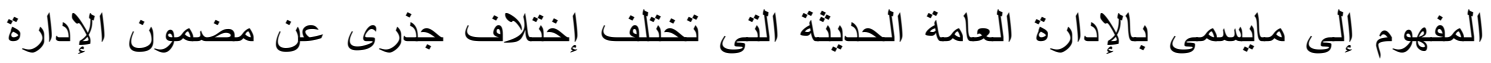

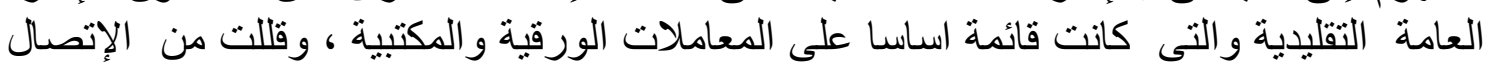

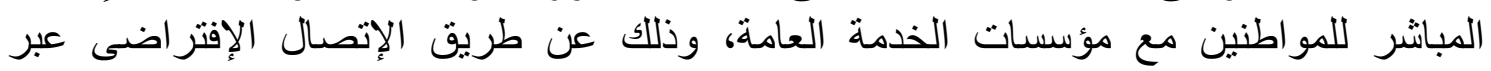

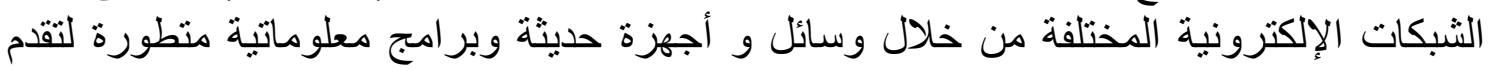
حلول للتعقيدات و المشاكل البيروقر اطية المتر اكمة.

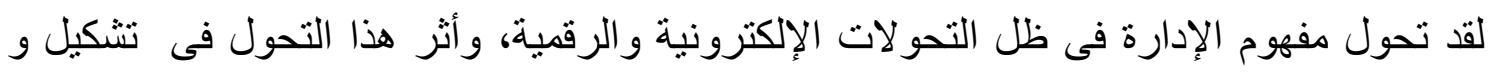

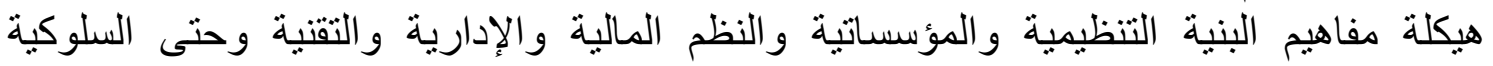
المرتبطة بسلوكيات الأفر اد . النظئ

و أصبح من الضروري على الحكومات مو اكبة هذا التغير واستخدام مميزاته حتى يكون أداة مهمة تساعد فى تطوير الخدمات الحكومية المقدمة للمو اطنين.

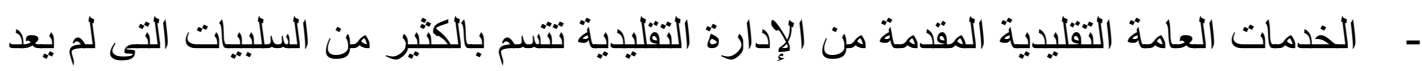

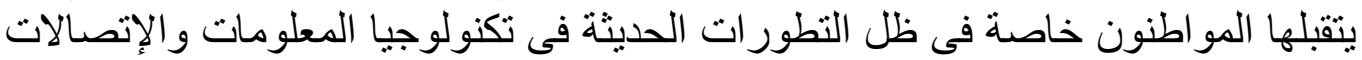

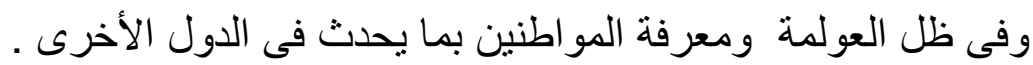

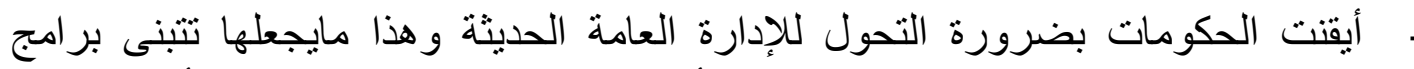

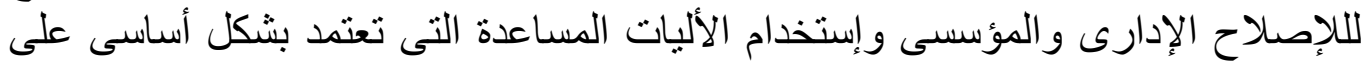

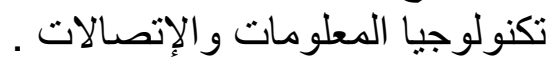

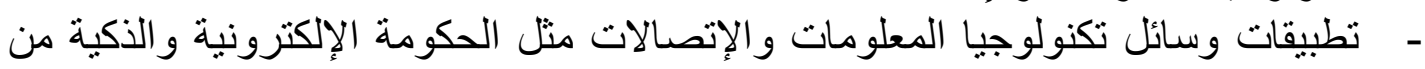

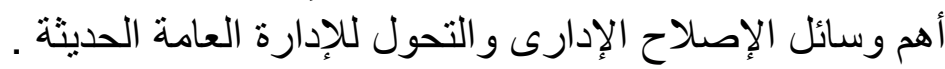

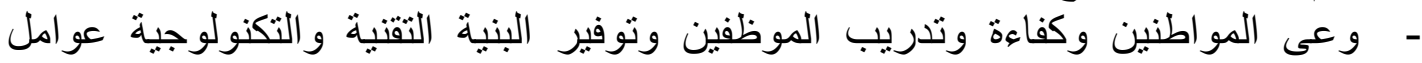

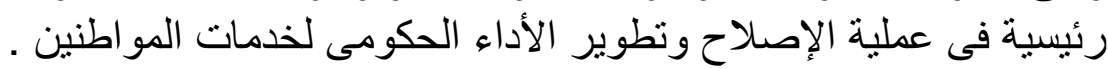

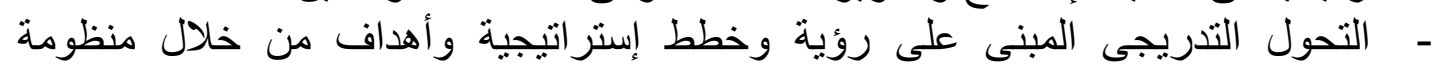

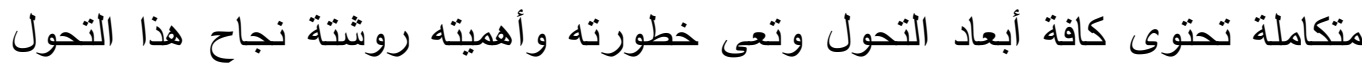

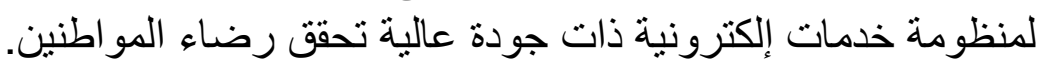

- من الضرورى لعملية التحول لخدمات عامة حديثة ذات جودة تتسم بالكفاء و الفعالية إجر اء تغيير

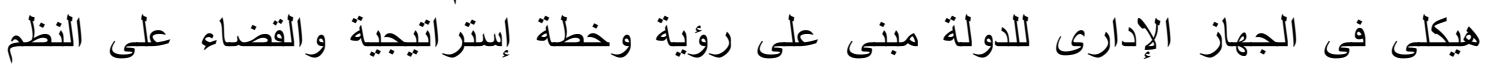

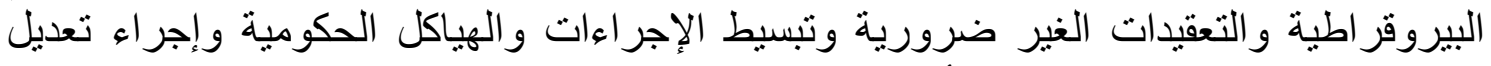

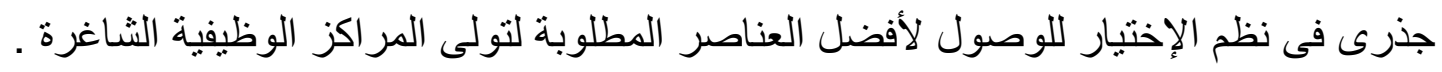




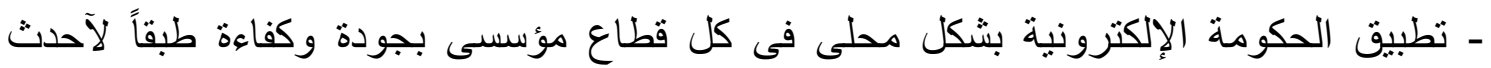

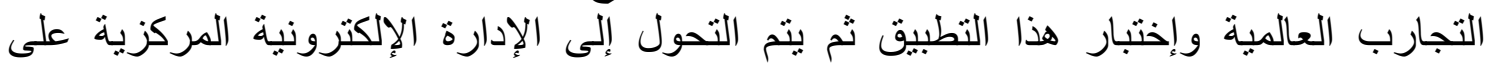

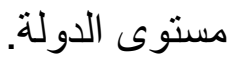

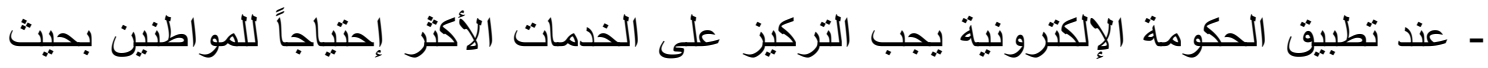

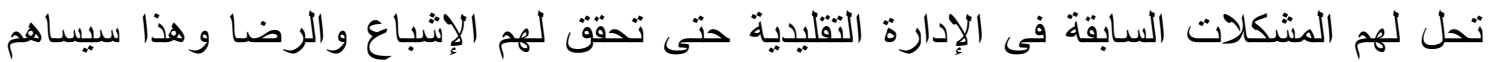

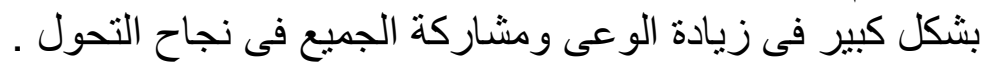
ـ إتباع الأسس الإقتصادية بالمقارنة بين التكلفة و العائد و القيام بجدوى إقتصادية لمشاريع الحكومة

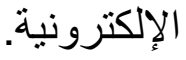

- تدعيم البنية التحتية الإلكترونية من خلال توفير شبكات نقل البيانات والإتصالات والأجهزة

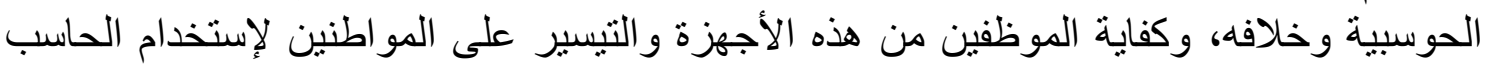

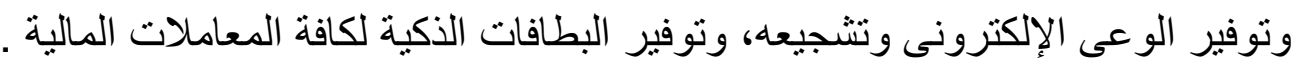
- توحيد المعايير الإكترونية بين جميع الوزارات وتوحيد نماذج تتسم بالسهولة فى إِتخدامها

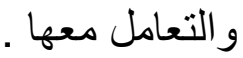

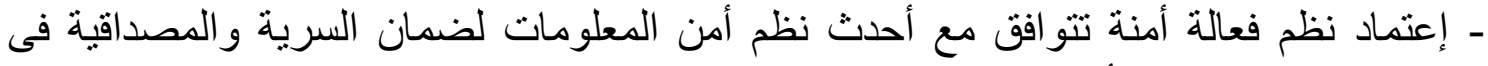
التعاملات وللحفاظ على أمن المواطن والدولة الدئة وتحقيق الثر عية القانونية . 


\section{English summary}

The public services, as defined by public administration experts, are the necessary needs for preserving human life and ensuring its well-being, which must be provided for the vast majority of the people.

It is the responsibility of the state in the first place. It is not a fixed time. It is a continuous process that the state should plan to present and develop in order for the citizen to obtain it in the best possible manner.

The tremendous progress in information and communications technology has forced governments and peoples to use their technologies, benefit from their advantages in public life and achieve many of the requirements through them, the most important of which is to provide good service to citizens and business sectors, and to achieve government transparency and enable citizens to access their services easily and easily. 


\section{المراجع العربية}

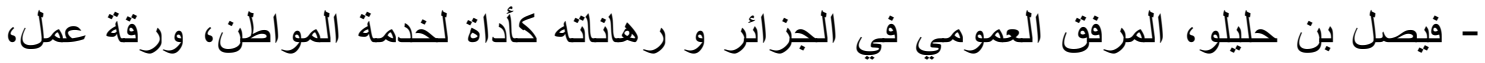

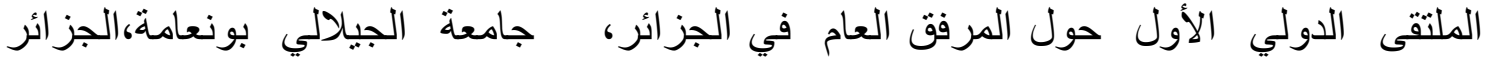
9 صن2015،

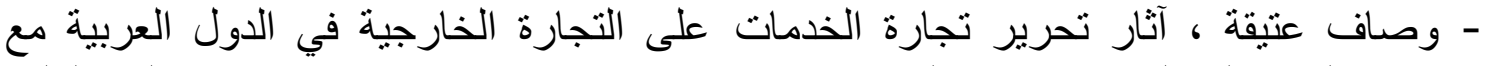

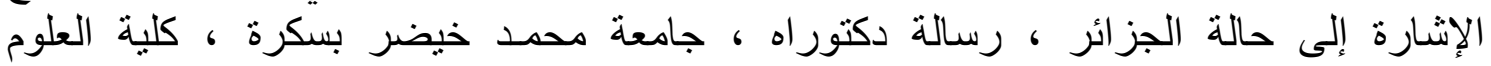

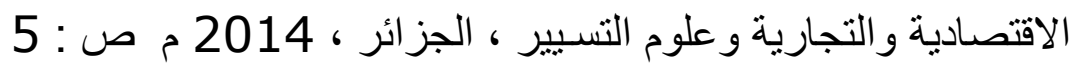
- محمد أمين عودة، إدارة المشروعات العامة_القضايا والاستراتيجيات ، جامعة الكويت ،

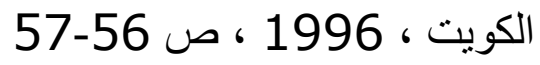

- هيثم عبداله ذيب، أصول التخطيط الإستراتيجى، دار البازورى،الإمارات العربية المتحدة 136 ـ 2017،

- عبد القادر درويش ، ليلى تكلا، أصول الإدارة العامة ، مكتبة الأنجلو المصرية ، مصر ،

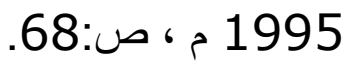

- مطلق السواط د.طلعت سندد. طلال الثريف، الإدارة العامة الدفاهيم- الوظائفــ الانشطة،

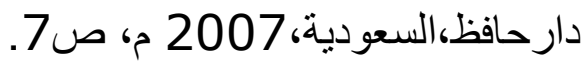

- على السلمى، الإدارة فى عصر العولمة والمعرفة ،دار سما ، مصر ، 2014 م ص 120 ـ محمد السعيد جوال ، ترقية أداء المنظمات العمومية في ظل مقاربة التسيير العمومي الجديد،

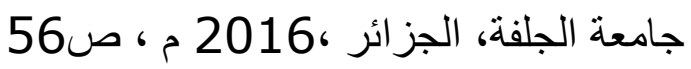
- مهذى نزيه ، محاضرات في التحليل المعاصر للإدارة العمومية ، كلية العلوم الإقتصادية

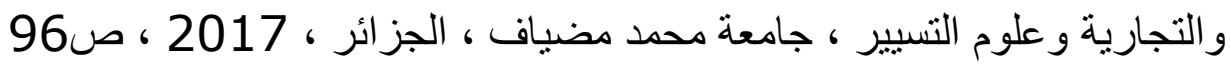
- نعمة عباس الخفاجى ،صلاح الدين الهيتى، تحليل أسس الإدارة العامة ـمنظور معاصر ،دار

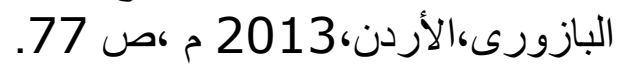

- مجدى عريف ، نظم المعلومات الإدارية ودورها فى حل مشكلات الإدارة العامة ،رسالة

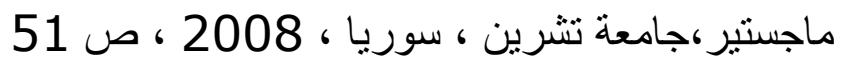

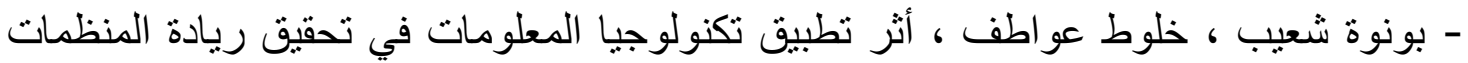

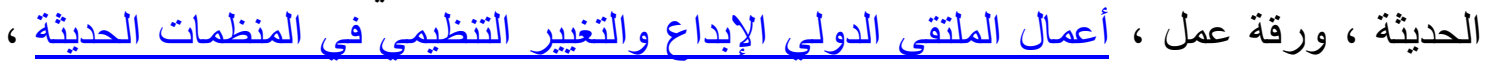
جامعة أبي بكر بلقايد، الجزائر ، 2011 م مرال صل : 9

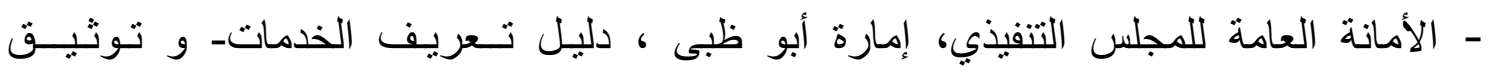

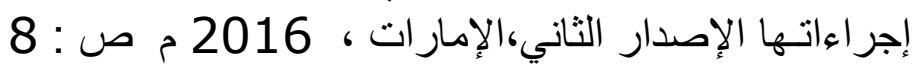

\section{English References}


- http://www.abahe.co.uk/customer-service-and-customer-careenc/64219-the-concept-of-

- http://misaa.wordpress.com/2008/05/29/public-administrationconcept

- http://www.arab-ency.com

- http://virtuelcampus.univ-msila.dz/facsegc/wp

- http://economicrg.blogspot.com.eg/2017/07/mehdi-nazih.html

- http://www.ahewar.org/debat/show.art.asp?aid=209173

- www.undp.org/content/dam/aplaws/publication/en/publications/dem ocratic-governance/dg-publications-for-website/publicadministration-reform-practice-note-/PARPN_English.pdf. 